\title{
Theoretical Pore Growth Models for Nanoporous Alumina
}

\author{
Chuan Cheng and A. H. W. Ngan \\ Department of Mechanical Engineering, The University of Hong Kong, Hong Kong, P. R. \\ China.
}

\begin{abstract}
Nanoporous alumina has been extensively used in a wide range of applications, including template materials for various types of nanomaterials, high surface-area structures for energy conversation and storage, bio/chemo sensors, electronic/photonic devices, and so on. However, the formation mechanism of the nanopores and the subsequent pore growth process towards self-ordered pore arrangements have been under investigation for several decades without clear conclusions. The present models may be divided into two main groups in terms of the driving force for pore initialization, as well as the subsequent pore growth process. One group considers that the driving force is the high electric field across the oxide barrier layer at the bottom of the pore channels, which assists metal oxidation at the metal/oxide interface, and oxide dissolution at the oxide/electrolyte interface. The other group of models assumes that the driving force is mechanical stress originating from the volume expansion of the metal oxidation process. This chapter reviews the development of these models for nanoporous alumina formation, and discusses their advantages and shortcomings. A recent model proposed by us is also described, and potential directions for further development are discussed.
\end{abstract}

\section{Introduction of nanoporous alumina}

Nanoporous alumina, also known as anodic aluminum oxide (AAO), has attracted extensive attention both experimentally and theoretically in the past several decades, due to the unique features such as self-ordered quasi-hexagonal nanoporous structures, relative ease to control the pore size and interpore distance by anodization conditions, extremely low cost, high thermal stability, and so on. ${ }^{1-21}$ Nowadays, AAO has been commercialized and widely used as convenient templates for non-lithographic synthesis of various nanomaterials, including nanodots, ${ }^{22-24}$ nanowires, ${ }^{25-29}$ nanotubes, ${ }^{30-32}$ and many others, ${ }^{33-35}$ for applications in high density magnetic media, ${ }^{36-41}$ photonic crystals, ${ }^{42-49}$ semiconductor devices, ${ }^{50-58}$ lithium-ion batteries,${ }^{59-62}$ solar cells, ${ }^{63,64}$ nanocapacitors, ${ }^{65-69}$ biosensors, ${ }^{70-76}$ and so on. ${ }^{77-88}$ 


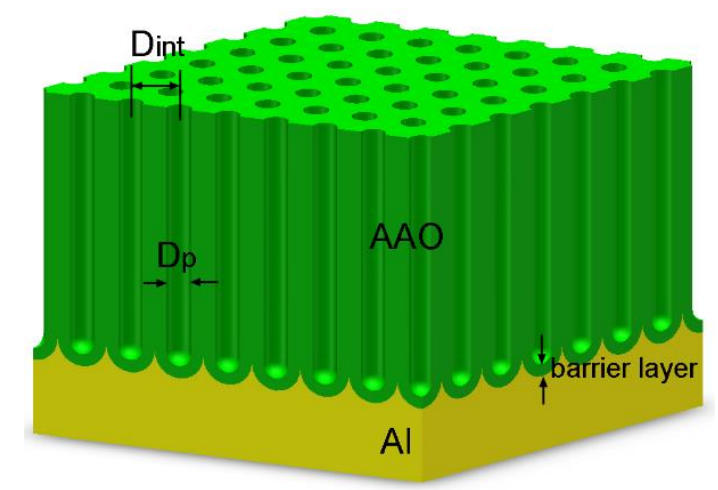

Figure 1. Schematic of self-ordered anodic aluminum oxide (AAO) formed above $\mathrm{Al}$ substrate, with interpore distance $\mathrm{D}_{\text {int }}$ and pore size $\mathrm{D}_{\mathrm{p}}$. A scallop-shaped oxide barrier layer exits between the porous layer and the $\mathrm{Al}$ substrate.

Nanoporous structured AAO can be easily fabricated by anodization of aluminum in different kinds of electrolytes, such as sulfuric acid ${ }^{89}$ oxalic acid, ${ }^{90-93}$ phosphoric acid, ${ }^{94}$ and chromic acid. ${ }^{94,95}$ However, for neutral electrolytes with $p H$ in the range of 5 to 7, only barrier-type alumina thin film can be formed. Here, we only focus on the former porous-type anodic alumina (AAO). Figure 1 illustrates the configuration of selfordered AAO, which consists of closely packed pore channels perpendicular to the $\mathrm{Al}$ substrate. The pore size $\left(D_{p}\right)$ and interpore distance $\left(D_{\text {int }}\right)$ can be varied from several to hundreds of nanometers mainly by changing of anodization voltages. ${ }^{57,92-94,96} \mathrm{~A}$ thin scallop-shaped oxide barrier layer exists between the porous AAO layer and Al substrate. It has been demonstrated for decades that the barrier layer thickness $D_{b}, D_{p}$, and $D_{\text {int }}$ have linear relationships with anodization voltage. ${ }^{2,3,94,97-99}$ The dependence may vary slightly with temperature and acid concentration. For example, under mild anodization (MA) conditions, the voltage dependence of $D_{p}$ and $D_{b}$ is about $1 \mathrm{~nm} \mathrm{~V}^{-1}$, and that of $D_{\text {int }}$ is 2.5 $\mathrm{nm} \mathrm{V}{ }^{-1} .{ }^{93,98}$ Recently, Lee et al. ${ }^{92}$ demonstrated that under hard anodization (HA) conditions in which the oxide growth rate is tens of micrometers per hour, the voltage dependency becomes $0.4 \mathrm{~nm} \mathrm{~V}^{-1}$ for the $D_{p}, 1 \mathrm{~nm} \mathrm{~V}^{-1}$ for $D_{b}$, and $2 \mathrm{~nm} \mathrm{~V}^{-1}$ for $D_{\text {int. }} A$ slight nonlinear relationship between $\mathrm{D}_{\text {int }}$ and anodiation voltage was recently reported by the authors under the high acid concentration and high temperature anodization (HHA) ${ }^{90}$ HHA can result in much better self-ordering AAO compared with MA in a voltage range from 30 to $60 \mathrm{~V}$ in oxalic acid based electrolyte, and reduce the time needed to reach self organization of the pores from typically two days in MA to only 2 to 3 hours in HHA.

From the top-view of self-ordered AAO, the pores are arranged in a quasihexagonal pattern. In real cases, ${ }^{100}$ the whole in-plane pattern usually exhibits local variations, with almost perfectly ordered zones separated by disordered zone boundaries. The average ordered zone size has been used as an effective factor to evaluate the ordering quality of AAO formed under different anodization conditions. ${ }^{90}$ AAO structures with self-ordered in-plane patterns also usually possess straight pore channels in their cross-sectional view, while those with disordered in-plane patterns usually have branched channels, with frequent splitting, termination, or merging of the pore channels. ${ }^{57,92-94,96}$ As a result, the aspect ratio of the pore channel, i.e. the channel length 
to pore diameter, can be greater than 1000 for self-ordered AAO, ${ }^{92,101,102}$ while the ratio may be less than 20 for disordered AAO. ${ }^{92,103}$ Because the in-plane porous patterns are just snap-shots during the growth of the AAO layer, it is the growth stability of pore channels during anodization which determines the self-ordering quality of AAO. In experiments, only under certain anodization conditions can self-ordered AAO with quasihexagonal in-plane porous patterns be fabricated, such as $25 \mathrm{~V}$ in $0.3 \mathrm{M} \mathrm{H}_{2} \mathrm{SO}_{4}$ at $\sim 0{ }^{\circ} \mathrm{C}$ with $D_{\text {int }}=63 \mathrm{~nm},{ }^{104} 40 \mathrm{~V}$ in $0.3 \mathrm{M} \mathrm{H}_{2} \mathrm{C}_{2} \mathrm{O}_{4}$ at $\sim 0{ }^{\circ} \mathrm{C}$ with $D_{\text {int }}=100 \mathrm{~nm},{ }^{93}$ and $195 \mathrm{~V}$ in $0.3 \mathrm{M} \mathrm{H}_{3} \mathrm{PO}_{4}$ at $\sim 0{ }^{\circ} \mathrm{C}$ with $D_{\text {int }}=500 \mathrm{~nm} .{ }^{105}$

a

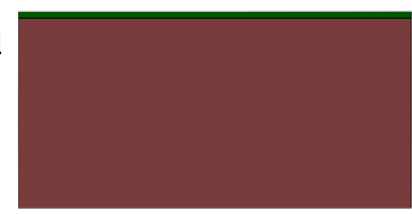

b
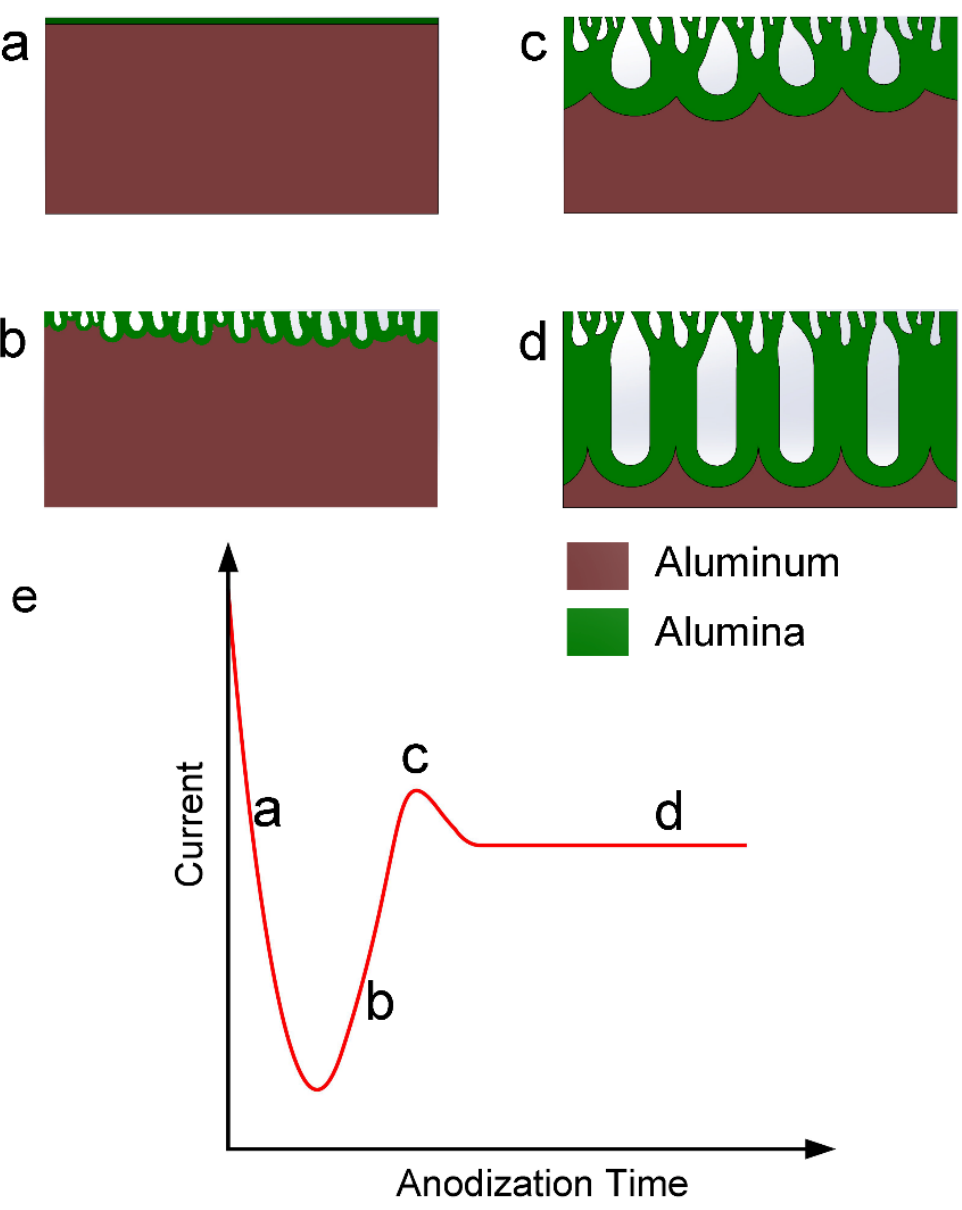

Figure 2. Schematic of anodic aluminum oxide (AAO) growth process under constant voltage condition. (a-d) Morphology development with anodization time increasing; (e) a typical current against anodization time relationship, with the corresponding morphologies marked along the curve.

A general AAO growth process under constant anodization voltage condition is illustrated in Fig. 2, in which four typical stages in terms of AAO morphologies are involved. At the beginning stage of anodization, as shown in Fig. 2(a), a thin and compact alumina film is quickly formed along the aluminum surface, resulting in blockage of the conductivity of the $\mathrm{Al}$ and a sharp decreasing of the current towards a 
minimum value. This process may only take several seconds to complete. Some roughness or concavity of the alumina film always exists due to the inhomogeneity of the aluminum surface, which may give rise to different oxide formation rates.

After that, as shown in Fig. 2(b), a large amount of small pores are initiated from the concavities of the rough alumina thin film. From the calculation of electric potential distribution within alumina, ${ }^{106}$ the electric potential drop is concentrated within a concaved region. As a result, a much higher electric field intensity exists within a concavity compared with a flat region. This gives rise to a faster oxide growth rate, namely, a small concavity continues penetrating into the aluminum substrate and develops into to a pore channel. These small pores, as illustrated in Fig. 2(b), are (i) randomly distributed; (ii) have no geometric relationship with anodization voltage (e.g. $\mathrm{D}_{\text {int/voltage ratio, }} \mathrm{D}_{\mathrm{p}} /$ voltage ratio); (iii) have their growth frequently terminated just at the surface region of the AAO. During the ignition of the pores, ion transportation takes place across the alumina film, mainly focusing at the pore bottom region in which the electric field is high enough to assist the ion migration. Thus, the previously blocked sample surface has ions passing through with give rise to an increase of the anodization current in Fig. 2(e).

With anodization time increasing, as shown in Fig. 2(c), some initial pores, which have larger depths into the Al substrate, will grow faster than their neighboring pores. At the same time, they will expand in the horizontal, in-plane direction. As a result, waterdrop shaped pore channels are developed, which have smaller pore mouths and larger pore bottoms, as shown in Fig. 2(c). In this stage, the development of the porous structure is driven by the electric field, which continuously adjusts the barrier layer thickness in order to reach a certain electric field distribution within it. This electric field assists the ion migration across the potential barriers, in order to realize ion migration within oxide and the electrochemical reactions at the interfaces. In experiments, different anodization voltages are found to lead to different barrier layer thickness but the electric field distribution is very similar, because the driving force (electric field) for ion migration within the alumina is intrinsic. Thus, the anodization voltage directly controls the geometry of the barrier layer at the bottom of the pores. With the pore bottom penetrating into the Al substrate, a pore channel is left behind, thus the electric field indirectly controls the geometry of the pore channels with time increasing. With a water-drop shaped pore bottom in Fig. 2(c), geometrically, the contact area between the barrier layer and aluminum substrate reaches a maximum compared with the cases in Figs. 2(b) and (d). As a result, the ion current, which mainly passes through the barrier layer, reaches a maximum value, as noted in Fig. 2(e).

After the stage of Fig. 2(c), walls of the pores elongated along the growth direction are formed and these have much reduced electric field intensity inside them due to their length in growth direction. Thus, the pore growth is mainly concentrated at the bottom of the pores towards the substrate, and as a result, the water-drop shape of the pores is developed into a U-shape, and accordingly the current slightly decreases, as shown in Fig. 2(e). After that, the geometry of the pore bottom tends to become stable, as a result the current reaches a steady-state value. However, this does not necessarily mean that the configuration of the pore bottom is fixed during this stage. Self origination of pores continuously takes place in terms of pore combination, splitting, and termination. 
The self-origination process first happens at the pore bottom and is then manifested by the trailing pore channels. It is during this stage that a disordered porous arrangement gradually develops into a much better self-ordering porous arrangement, which may take hours or days of anodization time. Thus, the self-ordering process takes place during the pore channel growth, after pores have already been initiated.

\section{Review of pore growth models}

The mechanism of pore growth in AAO has been continuously investigated for decades, and currently it is still under debate. ${ }^{1,95,107-127}$ In terms of the driving force for pore growth as well as the self-organization of pores towards ordering, the previous models may be divided into two types. One regards electric field as the driving force, , $^{2,94}$ while the other regards mechanical stress as the driving force. ${ }^{120,124,126}$

\subsection{Electric field assisted pore growth}

Hoar and Mott first proposed that the formation and growth of pores in AAO was assisted by electric field. ${ }^{108}$ They suggested that under the high electric field on the order of $1 \mathrm{~V} \mathrm{~nm} \mathrm{~nm}^{-1}$ across the oxide barrier layer, $\mathrm{O}^{2-}$ ions would be driven from the oxide/electrolyte interface to the metal/oxide interface for $\mathrm{Al}$ oxidation, while $\mathrm{Al}^{3+}$ ions would be driven by the electric field in the opposite direction, across the barrier layer and then ejected into the electrolyte. Ion migration in the barrier layer was proposed to take place by means of jumping from one interstitial position to another following the Cabrera-Mott equation. ${ }^{128}$ They emphasized that space charge should not be considered within the oxide, because the process of ion migration was comparatively easy.

O'Sullivan and Wood supported the idea that electric field assisted dissolution was the reason for pore formation and growth in AAO. ${ }^{94}$ They proposed that the thickness of oxide barrier layer was the result of a competition between oxidation and dissolution reactions at the pore bottom. The high electric field could stretch or break the Al-O bonds, thus aiding the dissolution of oxide and resulting in a faster rate than opencircuit chemical dissolution. ${ }^{2,3,94}$

Nagayama and Tamura ${ }^{129}$ demonstrated that during anodization the dissolution rate of the pore bottom was $1.04 \times 10^{-4} \mathrm{~cm} \mathrm{~min}^{-1}$ under $11.9 \mathrm{~V}$ and $9.4 \mathrm{~mA} \mathrm{~cm}^{-2}$, and this was about $10^{4}$ times faster than the rate of $7.5 \times 10^{-9} \mathrm{~cm} \mathrm{~min}^{-1}$ for the dissolution of the pores' inner surfaces, which can therefore be regarded as solely chemical dissolution. Moreover, by calculating the temperature distribution along the vertical pores, they demonstrated that the temperature rise at the pore bottom was always negligibly small at $\sim 0.06{ }^{\circ} \mathrm{C} .{ }^{130}$ Also, Mason ${ }^{131}$ and $\mathrm{Li}^{132,133}$ found that the temperature rise at the pore bottom was higher at about $25^{\circ} \mathrm{C}$, but even with this magnitude of temperature rise, the associated Joule heat would still be far insufficient to result in the observed high growth rate at the pore base. In fact Hunter and Fowle ${ }^{134,135}$ demonstrated that the electrolyte would have to reach boiling temperature in order for such fast growth to occur. Thus, the contribution of heat assisted dissolution of oxide should only play a minor role on pore growth during anodization. ${ }^{130}$ 
Several models in different mathematical forms have been developed by regarding the electric field as the driving force for pore growth. ${ }^{113-117}$ Parkhutik and Shershulsky proposed a model in which the electric potential in AAO obeyed Laplace equation by neglecting space charge within oxide and the electrochemical double layer along the oxide/electrolyte and metal/oxide interfaces. ${ }^{113}$ They proposed that the movement of oxide/electrolyte interface was due to the competition between oxide formation and electric field assisted dissolution, while the metal/oxide interface should move accordingly with the oxide/electrolyte interface. This model predicts a linear relationship between $D_{\text {int }}$ and anodization voltage, which was typically observed in experiments.

By using a linear and weakly nonlinear stability analysis, Thamida and Chang further developed the above model and predicated a critical $p H$ value of 1.77 for the transition from barrier-type to porous-type anodic alumina. ${ }^{114}$ Moreover, Singh et $a l{ }^{115,116}$ proposed a similar model by considering two situations: a long-wave instability resulting from electric field assisted dissolution, and a stabilizing effect of the Laplace pressure due to surface energy which provides a wavelength selection mechanism. They predicted that when the elastic stress in the oxide layer was significant, self-ordered pore arrays can be formed. ${ }^{116}$

However, Thamida et al.'s, Parkhutik and Shershulsky's, and Singh et al.'s models were challenged by Friedman et al.. ${ }^{99}$ For example, in their experiments $\mathrm{D}_{\text {int }}$ was independent of the electrolyte $p H$ at constant anodization voltage, ${ }^{99}$ whereas the former two models predict that $\mathrm{D}_{\text {int }}$ (in nm) should vary with the $p H$ according to $2.96 V_{o} /(2.31$ $1.19 \mathrm{pH}$ ), where $V_{0}$ is the constant anodization voltage. Although some of the predictions of these models do not agree with the experimental observations by Friedman et al. ${ }^{99}$ in some aspects, ${ }^{98,99}$ this does not necessarily mean that electric field is not the driving force for AAO growth and self-ordering, because previous models may not reflect the nature of electric-field assisted process correctly. Most recently, van Overmeere et al.$^{127}$ performed an energy-based perturbation analysis for pore growth in AAO, and they concluded that the electrostatic energy, rather than the mechanical strain energy-induced surface instability, was the main driving force for pore initiation as well as a controlling factor for pore spacing selection.

Furthermore, little efforts have been made to quantitatively investigate the electric field behavior by means of numerical simulation. For instance, in 2006, Houser and Hebert first numerically calculated the static electric potential distribution within AAO by considering the Laplace equation, as well as the Poisson equation in which the amount of space charge was artificially assumed to correlate with the distance from the pore axis. ${ }^{122}$ To our knowledge, no real-time evolution of the pore growth process during anodization has been simulated before our recent reports. ${ }^{106,136}$

\subsection{Mechanical stress assisted pore growth}

During oxidation reaction at the oxide barrier layer of AAO, significant volume expansion may take place at the oxide/metal interface. For instance, under $100 \%$ current efficiency without aby loss of $\mathrm{Al}^{3+}$, the volume expansion ratio, namely, the PillingBedworth ratio ${ }^{133,137,138}$, can reach 1.64 . However, it should be noted that direct loss of 
$\mathrm{Al}^{3+}$ ions (without oxide formation) can take place during anodization, ${ }^{139}$ which provides some spacing for the expanded volume and relief of the compression stress. For instance the measured ratio of the formed oxide thickness to the consumed aluminum thickness was 1.35 , which still indicates a large extent of volume expansion. ${ }^{140}$ Thus, the mechanical compression stress due to volume expansion was recently regarded as the driving force for pore growth in AAO, which was proposed to result in the plastic flow of oxide from the bottom to the walls of the pores. ${ }^{120,124,126}$ In particular, recent tungsten (W) tracer experiments seemed to support the idea that the AAO formed in phosphoric acid $^{141,142}$ and sulphuric acid ${ }^{143}$ was due to the plastic flow of the oxide. According to their explanation, if pores were formed by electric-field assisted dissolution, $\mathrm{W}$ tracers at the pore base would migrate ahead of the $\mathrm{W}$ tracers at pore walls, but they found the inverse. ${ }^{141-143}$ However, for the AAO formed in chromic acid ${ }^{144}$ and alkaline borate electrolyte, ${ }^{145,146}$ the $\mathrm{W}$ tracer distribution in the oxide was relatively uniform which suggests that the pore formation is due to electric-field assisted dissolution of oxide. ${ }^{144-146}$ It is not clear why the pore formation mechanism was different in different types of electrolyte, since the electrolyte species were found not to participate in the oxide formation reaction. ${ }^{142}$

Furthermore, by using the same electrolyte of phosphoric acid ${ }^{141,142}$ but different tracers ${ }^{147,148}$ of $\mathrm{Nd}$ and $\mathrm{Hf}$, the tracer migration distribution within the oxide was found to be the reverse of that previously found for $\mathrm{W}$ tracer, ${ }^{141-143}$ and this would indicate electric-field assisted dissolution as the pore formation mechanism, just as the previously found $\mathrm{W}$ distribution would indicate oxide flow as the mechanism. The unexpected $\mathrm{Nd}$ and $\mathrm{Hf}$ tracer distribution was attributed to the faster migration rate of the tracer atoms compared with that of $\mathrm{Al}$ ions. ${ }^{147,148}$ However, as noticed by $\mathrm{Oh},{ }^{135}$ a tracer study alone cannot yield sufficient evidence to prove oxide flow or disprove electric-field assisted dissolution as the mechanism for pore formation.

For the stress-driven self-ordering of AAO, Jessensky et al. ${ }^{120,149}$ proposed that repulsive forces between neighboring pores of AAO can arise during anodization due to the volume expansion. A moderate anodization voltage was found to result in a moderate magnitude of the current efficiency as well as volume expansion ratio, and only under these moderate conditions can self-ordered AAO be obtained. However, an important question is whether it is the moderate electric voltage (related to electrostatic energy) or the moderate volume expansion ratio (related to mechanical energy) which really causes the ordering in the porous structure. These two factors cannot be separated in their experiments, and so sufficient evidence has not been established to support that the main reason for self-ordering in AAO is due to the mechanical stress.

Recently, Houser and Hebert ${ }^{125,126}$ proposed a mathematical model for the steady state growth of $\mathrm{AAO}$, in which the $\mathrm{Al}^{3+}$ and $\mathrm{O}^{2-}$ ions are transported by electrical migration and viscous flow. A good agreement between their calculation results and $\mathrm{W}$ tracer experimental results was obtained. ${ }^{141-143}$ However, as discussed by Oh, ${ }^{135}$ a close examination of the boundary conditions used in this oxide flow model would show that the new oxide would be generated at the oxide/electrolyte interface (by the so-called oxygen deposition), which was inconsistent with the observation from $\mathrm{O}^{18}$ tracer experiments that the new oxide was only found at the metal/oxide interface. ${ }^{139}$ 


\section{A kinetics model for pore channel growth in nanoporous alumina}

Recently, we have developed a kinetics model for pore-channel growth as well as self-organization towards ordering in AAO. ${ }^{106}$ This model is a further development of previous models by regarding electric field as the driving force. ${ }^{113-116}$ The Laplacian electric potential distribution and continuity of the current density within the oxide body are considered. Both oxygen and aluminum ion current densities governed by the Cabrera-Mott equation in high-electric-field theory are formed by ion migration within the oxide as well as across the oxide/electrolyte and metal/oxide interfaces. The movements of oxide/electrolyte and metal/oxide interfaces are due to electric-field assisted oxide decomposition and metal oxidation, respectively, as governed by Faraday's law. This model has been numerically implemented by a finite element method in order to simulate the real-time evolution of the porous structure growth in two-dimensional cases corresponding to the cross-sectional view of pore channels. ${ }^{106,136}$

\subsection{Electric potential distribution within AAO}

As has been reported by Houser and Hebert, ${ }^{122}$ during anodization, space charge within the anodic oxide may significantly influence the electric field distribution there. Although space charge was considered by Dewald ${ }^{150,151}$ to successfully explain the experimentally observed temperature-independent Tafel slope in the formation of barriertype anodic tantalum oxide, Vermilyea ${ }^{152}$ found that Dewald's consideration was unable to explain the experimental fact that the average electric field is independent of the thickness of the anodic oxide film. Thus, whether space charge should be considered during anodization still needs further investigations, and here, following Parkhutik and Shershulsky, ${ }^{113}$ Thamida and Chang, ${ }^{114}$ and Singh et al. ${ }^{115,116}$ we neglect space charge within the oxide. Thus, the electric potential $\varphi$ within the oxide obeys the Laplace Equation:

$$
\nabla^{2} \varphi=0 \text {. }
$$

According to Houser and Hebert, ${ }^{122}$ the potential at the oxide/electrolyte interface (typically $<0.1 \mathrm{~V}$ ) is far smaller than the anodization voltage, and so in the present model, the potential there is set to be zero. In addition, as most of the potential drop happens within the oxide body but not in the metal substrate or in the electrolyte, the potential at the metal/oxide interface is set to be the same as the anodization voltage $V_{0}$. In this chapter, we only investigate anodization under constant voltage conditions. Moreover, along the right and left edges of a simulation sample (e.g. the vertical dash dotted lines in Fig. 3), the Neumann boundary condition is used. Thus, the boundary conditions are summarized as

$$
\begin{cases}\varphi=0, & \text { at metal/oxid e interface, } \\ \varphi=V_{0}, & \text { at oxide/elec troly teinterface, } \\ \mathbf{n} \cdot \nabla \varphi=0, & \text { at both edges of the sample, }\end{cases}
$$

where $\mathbf{n}$ is the outward normal unit vector for each sample edge. The electric field is given as 
$\mathbf{E}=-\nabla \varphi$.

The continuity requirement of the steady-state ion-current density $\mathbf{j}$ within the oxide bulk can be expressed as follows ${ }^{113-116}$

$\nabla \cdot \mathbf{j}=0$.

From the above equations, we can derive the relationship between the electric field and current density along the electric-field lines across the oxide barrier layer, which will be used later. Electric-field lines are always perpendicular to equipotential contours. Consider a very small cylinder with volume $V_{\mathrm{c}}\left(V_{c} \rightarrow 0\right)$, which starts from the metal/oxide interface to the oxide/electrolyte interface along an electric-field line across the oxide barrier layer. The top and bottom surfaces of the cylinder are elements of the oxide/electrolyte and metal/oxide interfaces with areas represented as $S_{\mathrm{o} / \mathrm{e}}$ and $S_{\mathrm{m} / \mathrm{o}}$, respectively. $S_{\mathrm{o} / \mathrm{e}}$ and $S_{\mathrm{m} / \mathrm{o}}$ are not equal because of the scalloped shape of barrier layer. The side surface $S_{\text {side }}$ of the cylinder is along the electric-field line, so that its outward normal vector is perpendicular to the electric-field line. From Eqs. (1) and (5), we get $\nabla \cdot \mathbf{E}=0$, and with Gauss' Theorem $\oiiint_{V_{c}}(\nabla \cdot \mathbf{E}) d V=\oiint_{S_{c}}(\mathbf{E} \cdot \mathbf{n}) d S$, we have

$\iint_{S_{o / e}}(\mathbf{E} \cdot \mathbf{n}) d S_{o / e}+\iint_{S_{m / o}}(\mathbf{E} \cdot \mathbf{n}) d S_{m / o}+\iint_{S_{\text {side }}}(\mathbf{E} \cdot \mathbf{n}) d S_{\text {side }}=0$.

Since $\mathbf{E} \cdot \mathbf{n}=0$ over $S_{\text {side }}, \mathbf{E}=\mathbf{n} E_{\text {o/e }}$ over $S_{\mathrm{o} / \mathrm{e}}$, and $\mathbf{E}=-\mathbf{n} E_{m / o}$ over $S_{\mathrm{m} / \mathrm{o}}$, where $E_{\mathrm{o} / \mathrm{e}}$ and $E_{\mathrm{m} / \mathrm{o}}$ are the electric field intensities at $S_{\mathrm{o} / \mathrm{e}}$ and $S_{\mathrm{m} / \mathrm{o}}$, respectively, and as $S_{\mathrm{o} / \mathrm{e}}$ and $S_{m / o}$ both tend to zero, Eq. (2.7) becomes

$E_{o / e} S_{o / e}=E_{m / o} S_{m / o}$,

where $S_{\mathrm{o} / \mathrm{e}}$ and $S_{m / o}$ are connected by the same electric-field line. By virtue of Eq. (6) which is of the same form as $\nabla \cdot \mathbf{E}=0$, the above procedure can be repeated for $\mathbf{j}$ to give

$j_{o / e} S_{o / e}=j_{m / o} S_{m / o}$,

where $j_{o / e}$ and $j_{m / o}$ are the current density magnitudes at $S_{o / e}$ and $S_{m / o}$ respectively. From Eqs. (8) and (9), we obtain

$\frac{j_{o / e}}{j_{m / o}}=\frac{E_{o / e}}{E_{m / o}}$.

The same derivation process actually holds for any point within the oxide bulk with electric-field intensity $E_{\text {bulk }}$ and current density $j_{\text {bulk, }}$

$$
\frac{j_{*}}{j_{b u l k}}=\frac{E_{*}}{E_{b u l k}},
$$

where the subscript "*" represents either "o/e" or " $\mathrm{m} / \mathrm{o}$, and the oxide bulk point and the o/e (oxide/electrolyte) or m/o (metal/oxide) interface point should be connected by the same electric-field line. Eq. (10) was first cited before by Parkhutik and Shershulsky, ${ }^{113}$ without proof, and its significance, together with that of Eq. (11), is as follows. For a given porous structure of AAO, the electric-field intensities can be solved directly from Eqs. (1-5). After that, regardless of whether the rate-determining step of the anodization 
process is at the oxide/electrolyte interface, oxide bulk, or metal/oxide interface, if we can calculate the current density at one location, e.g. the oxide/electrolyte interface, we can obtain the current density at other locations by using Eqs. (10) and (11) directly. The location at which the current density is first evaluated may not necessarily be the location at which the rate-determining step occurs, but the calculated current density will be controlled by the rate-determining step through Eq. (11). Here, we assume that ion migration across the oxide/electrolyte interface is the rate-determining step, because the oxygen and aluminum ions are weakly bound under the effect of the high electric field. ${ }^{94}$ It should be noted that ionic migration in the bulk oxide has been proposed previously as an alternative rate-determining step, ${ }^{153}$ but recent experiments revealed that an increase in the acid concentration of the electrolyte, which should play a role directly at the oxide/electrolyte interface, can influence the anodization process significantly, such as increasing the pore diameter, ${ }^{98}$ the current density, ${ }^{154}$ and the oxide growth rate. ${ }^{99}$ These profound changes of the anodization process should be due to changes in the anodization conditions at the oxide/electrolyte interface, and this is the basis of the present assumption that the rate-determining step is at this interface. In the following, the current density at the oxide/electrolyte interface is derived at first, and then the current density at the metal/oxide interface is obtained from Eq. (10). Based on these, the interface movement equations are established from Faraday's Law.

\subsection{Ion migration}

In AAO formation, Cherki and Siejka's oxygen transport study using nuclear microanalyses of $\mathrm{O}^{18}$ and $\mathrm{O}^{16}$ concluded that new oxide forms only at the metal/oxide interface but not elsewhere. ${ }^{139}$ Also, Davies et al. ${ }^{155,156}$ found that $\mathrm{Xe}^{125}$ and $\mathrm{Rn}^{222}$ tracer distributions in barrier-type anodic alumina films did not tend to broaden. These experimental observations imply that the oxidation reaction within the oxide body is negligible. On this basis we assume that the cations and anions migrating from one interface to another interface are not consumed on their way. On the oxide/electrolyte and metal/oxide interfaces, as shown in Fig. 3, the most possible reactions based on previous experimental observations are described in the following subsections. 

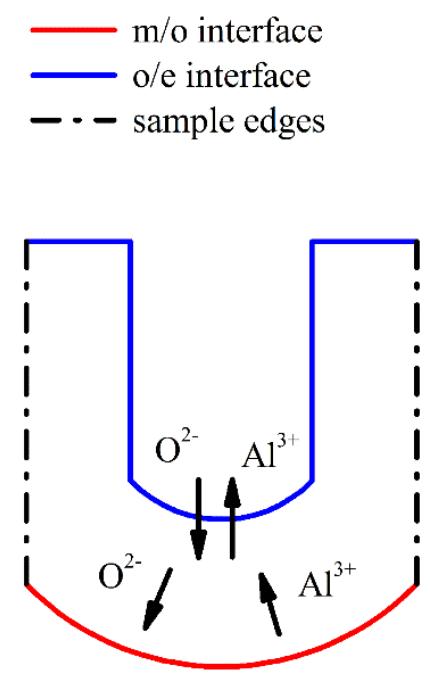

Reactions at the o/e Interface:

(R2) $\mathrm{Al}_{(\mathrm{ox})}^{3 !} \rightarrow \mathrm{Al}_{(\mathrm{aq})}^{3 !}$

(R3) $\mathrm{Al}_{2} \mathrm{O}_{3(\mathrm{ox})} \rightarrow 2 \mathrm{Al}_{(\mathrm{aq})}^{3+}+3 \mathrm{O}_{(\mathrm{ox})}^{2-}$

(R5) $\mathrm{H}_{2} \mathrm{O}_{\text {(aq) }} \rightarrow 2 \mathrm{H}_{(\text {(aq) }}^{+}+\mathrm{O}_{(\text {ox) }}^{2-}$
Reactions at the $\mathrm{m} / \mathrm{o}$ Interface:
(R1) $\mathrm{Al}_{(\mathrm{m})} \longrightarrow \mathrm{Al}_{(\mathrm{ox})}^{3+}+3 \mathrm{e}^{-}$
Curent densities
(R4) $2 \mathrm{Al}_{(\mathrm{m})}+3 \mathrm{O}_{(\mathrm{ox})}^{2-} \rightarrow \mathrm{Al}_{2} \mathrm{O}_{3(\mathrm{ox})}+6 \mathrm{e}^{-}$
Producing $\left.\mathbf{j}_{A, o x}\right|_{m / o}$ at $\mathrm{m} / \mathrm{o}$ interface, and becomes $\left.\mathbf{j}_{A l, o x}\right|_{o / e}$ at o/e interface.
Supplied by $\left.\mathbf{j}_{O, o x}\right|_{\mathrm{o} / \mathrm{c}}=\mathbf{j}_{O, \text { o/ }}+\mathbf{j}_{O, \text { dis }}$ at $\mathrm{o} / \mathrm{e}$
interface and becomes $\left.\mathbf{j}_{O, o x}\right|_{m / o}$ at $\mathrm{m} / \mathrm{o}$
interface.
Supplied by $\left.\mathbf{j}_{A l, o x}\right|_{m / \mathrm{o}}$ at $\mathrm{m} / \mathrm{o}$ interface and becomes $\left.\mathbf{j}_{A l, o x}\right|_{o / c}$ at $\mathrm{o} / \mathrm{e}$ interface, together with $\mathbf{j}_{A, \text { dis }}$ from oxide decomposition at $\mathrm{o} / \mathrm{e}$ interface; total value for $\mathrm{Al}^{3+}$ across o/e interface is $\mathbf{j}_{A l, o / e}=\left.\mathbf{j}_{\text {Al,ox } / \mathrm{c}}\right|_{\text {il, dis }}$.
Producing $\mathbf{j}_{\text {Al,dis }}=\mathbf{j}_{\ell, \text { dis }}$, in which
$\mathrm{Al}^{3+}$ ejected into electrolyte;
$\mathrm{O}^{2-}$ migrating towards $\mathrm{m} / \mathrm{o}$ interface.
Producing $\mathbf{j}_{O, \text { o/e }}$ at o/e interface, in which
$\mathrm{O}^{2-}$ migrating towards $\mathrm{m} / \mathrm{o}$ interface.

Ion Current Density Across the o/e Interface:

$\mathrm{Al}^{3+}$ ions ejected into electrolyte: $\mathbf{j}_{A l, o / e}=\left.\mathbf{j}_{A l, o x}\right|_{o / e}+\mathbf{j}_{A l, d i s}$ due to R1, R2 and R3.

$\mathrm{O}^{2-}$ ions supplied by clectrolyte : $\mathbf{j}_{O, O / e}=\left.\mathbf{j}_{O, o x}\right|_{O / e}-\mathbf{j}_{O, d i s}$ duc to R3, R4 and R5.

Figure 3. Summary of the reactions assumed during AAO growth. o/e means oxide/electrolyte interface, and $\mathrm{m} / \mathrm{o}$ means metal/oxide interface. (Adapted from Ref. 106.)

\subsubsection{Aluminum ion migration}

Direct ejection of aluminum ions from the metal/oxide interface into the electrolyte has been indicated in many experiments, such as coating-ratio measurement and tracer experiments. The coating ratio, defined as the weight of the oxide formed to the weight of aluminum consumed in the anodization process, will be 1.89 if all of the consumed aluminum is converted into alumina, or higher if acid anions contaminate the anodic oxide, e.g. 2.2 if $14 \% \mathrm{SO}_{3}$ contamination exists in the oxide. ${ }^{1}$ After considering the porosity (around $10 \%)^{157}$ of the oxide due to its dissolution in the electrolyte, the coating ratio should be about 1.7 (or 1.98 if $14 \% \mathrm{SO}_{3}$ contamination exists). However, experimentally observed values of the coating ratio are always lower. For example, Edwards and Keller ${ }^{158}$ found that the coating ratio was smaller than about 1.46. Spooner ${ }^{159}$ attempted to obtain a high coating ratio by increasing the current density and decreasing the dissolution rate in sulfuric acid (with $\mathrm{SO}_{3}$ contamination in the oxide), but only 1.68 was obtained, and under other conditions the coating ratio was lower than 1.61. These imply that $\mathrm{Al}$ must be lost by another way beside the loss due to pore growth at the pore base assisted by the high electric field there, and this cannot be oxide dissolution loss at the pore walls or top surface, as these dissolution rates were found to be far smaller on the order of $10^{-8} \mathrm{~cm} \mathrm{~min}^{-1},{ }^{129,139}$ compared with the dissolution rate of $\sim 10^{-4}$ $\mathrm{cm} / \mathrm{min}$ at the pore base. ${ }^{129}$ A similar conclusion was reached by Cherki and Siejka from their $\mathrm{O}^{18}$ tracer experiments, ${ }^{139}$ which indicated that direct ejection of $\mathrm{Al}$ cations in the 
solution without formation of any oxide should take place. Recent experiments by Wu et $a l{ }^{160}$ also support the net ejection of $\mathrm{Al}^{3+}$ cations across the barrier layer into the electrolyte. Thus, it is reasonable to assume that $\mathrm{Al}^{3+}$ cations formed at the metal/oxide interface via the reaction

$$
\mathrm{Al}_{(\mathrm{m})} \rightarrow \mathrm{Al}_{(\mathrm{ox})}^{3+}+3 \mathrm{e}^{-}
$$

would reach the oxide/electrolyte interface under the drive of the high electric field, and are finally ejected into the solution by the reaction

$$
\mathrm{Al}_{(\mathrm{ox})}^{3+} \rightarrow \mathrm{Al}_{(\mathrm{aq})}^{3+}
$$

without oxide formation. R1 is the only source of the aluminum ions migrating through the oxide body from the metal/oxide to oxide/electrolyte interface during the anodization process, and the density of such current is denoted as $\mathbf{j}_{A l, o x}$, where "ox" means that the corresponding aluminum ions migrate through the oxide body. The value of $\mathbf{j}_{A l, o x}$ at the metal/oxide interface is denoted as $\mathbf{j} A l,\left.o x\right|_{m / o}$, while that at the oxide/electrolyte interface is denoted as $\mathbf{j}$ Al,ox $\left.\right|_{\text {ole }}$.

For AAO formation, we must note that those aluminum ions which have traveled across the oxide barrier layer do not react to form new oxide at the oxide/electrolyte interface, because new oxide was found to form only at the metal/oxide interface but not at the oxide/electrolyte interface. ${ }^{139}$ The situation in barrier-type (i.e. nonporous-type) anodic alumina film formation is, however, different, since new oxide was found to form at both the metal/oxide and oxide/electrolyte interfaces. ${ }^{155,161}$ In other words, a net aluminum current passes through the oxide barrier layer in both cases of barrier-type and porous-type alumina formation, but whether the aluminum ions reaching the oxide/electrolyte interface can form new oxide there would determine the type of alumina finally formed. We surmise that the acid concentration or the $p H$ of the electrolyte would determine the fate of the aluminum ions migrated to the oxide/electrolyte interface, and in the model development below, this effect will be incorporated (see Eq. (15) later).

In addition to the direct ejection of aluminum ions, dissolution of the old oxide to form pores should take place at the oxide/electrolyte interface, which is thought to be also electric-field assisted, because of the extremely fast dissolution rate at the pore base $\left(\sim 10^{-}\right.$ $\left.{ }^{4} \mathrm{~cm} \mathrm{m^{-1 }}\right)$ compared with the rate at the pore walls $\left(\sim 10^{-8} \mathrm{~cm} \mathrm{~min}^{-1}\right)$ as found in experiments. ${ }^{129,139}$ Such a great difference in the dissolution rates should be mainly due to the large difference in electric-field intensities between these two locations. Furthermore, Siejka and Ortega's $\mathrm{O}^{18}$ tracer experiments ${ }^{162}$ showed that oxygen loss during pore formation is negligible, which would contradict the dissolution reaction $\mathrm{Al}_{2} \mathrm{O}_{3(\mathrm{ox})}+6 \mathrm{H}_{(\mathrm{aq})}^{+} \rightarrow 2 \mathrm{Al}_{(\mathrm{aq})}^{3+}+3 \mathrm{H}_{2} \mathrm{O}_{(\mathrm{aq})}$ assumed in some previous studies, ${ }^{114,133}$ since this reaction would involve the loss of oxygen from the oxide into the electrolyte. Instead, the old oxide at the pore base is likely to be consumed by the following decomposition reaction: ${ }^{162}$

$$
\mathrm{Al}_{2} \mathrm{O}_{3(\mathrm{ox})} \rightarrow 2 \mathrm{Al}_{(\mathrm{aq})}^{3+}+3 \mathrm{O}_{(\mathrm{ox})}^{2-},
$$

in which the product oxygen remains in the oxide body, and is then driven by the high electric field to reach the metal/oxide interface to form new oxide there. Thus, the so- 
called "electric-field assisted dissolution of oxide" referred to by some previous researchers ${ }^{2,94,110}$ is interpreted here as the electric-field assisted decomposition of oxide at the oxide/electrolyte interface. Let $\mathbf{j}_{\text {o,dis }}$ and $\mathbf{j}_{A l \text {,dis }}$ denote the oxygen ion and aluminum ion current density due to R3 at the oxide/electrolyte interface. Their values are equal, but the corresponding ion movements are in opposite directions, i.e.

$\mathbf{j}_{A l, d i s}=\mathbf{j}_{o, d i s}$.

The experimentally established electric-field assisted ejection of aluminum ions into the electrolyte, the current density of which is denoted as $\mathbf{j}_{A l, o / e}$ hereafter, is contributed by aluminum ions produced by oxide decomposition at the o/e interface (of current density $\mathbf{j}_{\text {Al,dis }}$ in R3), as well as ions migrated from the metal/oxide interface (of current density $\left.\mathbf{j}_{A l, o x}\right|_{\mathrm{o} / \mathrm{e}}$ in R2), i.e.

$\mathbf{j}_{A l, o / e}=\left.\mathbf{j}_{A l, o x}\right|_{o / e}+\mathbf{j}_{A l, d i s}$.

At the oxide/electrolyte interface, although the aluminum ions ejected into the electrolyte come from two sources, the actual ejection process which is reaction R2 has no difference from an electrolyte point of view. Physically, this process is governed by the high-field theory ${ }^{4,128,163}$ in which the aluminum ions are assumed to jump across a potential barrier $W_{A l}$ at the oxide/electrolyte interface, the effective value of which is reduced by an amount $\alpha_{A l} a_{A l} q_{A l} E_{o / e}$ in the jumping direction along the electric field $E_{o / e}$, and increased by $\left(1-\alpha_{A l}\right) a_{A l} q_{A l} E_{o / e}$ in the opposite direction. Thus, the $\mathbf{j}_{A l, o / e}$ can be expressed as the Cabrera-Mott equation, ${ }^{128}$

$\mathbf{j}_{A l, o / e}=\left\{n_{A l} q_{A l} v_{A l} \exp \left(-\frac{W_{A l}-\alpha_{A l} q_{A l} a_{A l} E_{o / e}}{k T}\right)-n_{A l} q_{A l} v_{A l} \exp \left[-\frac{W_{A l}+\left(1-\alpha_{A l}\right) q_{A l} a_{A l} E_{o / e}}{k T}\right]\right\} \hat{\mathbf{E}}_{o / e}$

where $n_{A l}$ is the surface density of mobile aluminum ions at the oxide/electrolyte interface which is dependent on electric intensity, ${ }^{4} q_{A l}$ is the charge of one aluminum ion, $v_{A l}$ is the vibration frequency of aluminum ions, $\alpha_{A l}$ is a transfer coefficient related to the symmetry of the potential barrier (e.g. if the potential barrier is symmetrical, then $\alpha_{A l}=0.5$ ), $a_{A l}$ is the jump distance (twice the activation distance) of aluminum ions, $\mathbf{E}_{o / e}$ is the electric field at oxide/electrolyte interface, $E_{o / e}=\left|\mathbf{E}_{o / e}\right|$ is the electric field intensity, $\hat{\mathbf{E}}_{o / e}$ is the unit vector $\mathbf{E}_{o / e} / E_{o / e}, k$ is the Boltzmann constant, and $T$ is the absolute temperature. The Cabrera-Mott equation above contains terms that describe jumps in both the forward and backward directions, but in practice, the backward current density (the second term in Eq. (14)) is far smaller than the forward one (the first term in Eq. (14)), ${ }^{163}$ and so to save computation time only the forward current was considered in the present numerical simulations. Furthermore, following Diggle ${ }^{110}$ and Vermilyea, ${ }^{164}$ to describe the fact that the dissolution process is strongly influenced by the acid concentration $C_{H^{+}}$, the current density is scaled by the factor $\left(C_{H^{+}}\right)^{\eta}$, where $\eta=\alpha / \varsigma \in[0,1]$ is the ratio of the number of protons $\alpha$ involved in the dissolution process to the stoichiometric number $\varsigma$ appropriate to the dissolution mechanism. ${ }^{110}$ This power term $\left(C_{H^{+}}\right)^{\eta}$ was also used in previous reports. ${ }^{113-116}$ Diggle $^{110}$ stated that only the current of the ion species involved in the rate 
determining process should be scaled by $\left(C_{H^{+}}\right)^{\eta}$, and here, we believe that aluminum ions rather than oxygen ions are more likely the rate controlling species, since, as discussed above, aluminum ions need to jump across a high potential barrier at the oxide/electrolyte interface to enter the electrolyte, while oxygen ions migrate within the oxide body towards the metal/oxide interface, and such migration can take place along some easy paths such as microchannels ${ }^{139,165,166}$ or by vacancy motion. ${ }^{162}$ Thus, after neglecting the backward current density and scaling the current density by the acid concentration in Eq. (14), the total aluminum ion current which goes into the electrolyte is given as

$\mathbf{j}_{A l, o / e}=n_{A l} A_{A l} \exp \left(k_{A l} E_{o / e}\right) \hat{\mathbf{E}}_{o / e}$,

where $A_{A l}=C_{H^{+}}^{\eta} q_{A l} v_{A l} \exp \left(-W_{A l} / k T\right)$ and $k_{A l}=\alpha_{A l} q_{A l} a_{A l} / k T$.

\subsubsection{Oxygen ion migration}

According to Cherki and Siejka's oxygen transport study, ${ }^{139}$ new oxide is only formed at the metal/oxide interface, but not at the electrolyte/barrier layer interface or at the outer surface of the porous film. This means that $\mathrm{O}^{2-}$ ions have to migrate from the oxide/electrolyte interface to the metal/oxide interface across the barrier layer under the high electric field. Once the oxygen ions reach the metal/oxide interface, the following reaction may take place:

$$
2 \mathrm{Al}_{(\mathrm{m})}+3 \mathrm{O}_{(\mathrm{ox})}^{2-} \rightarrow \mathrm{Al}_{2} \mathrm{O}_{3(\mathrm{ox})}+6 \mathrm{e}^{-} \text {. }
$$

R4 accounts for the entire migration of oxygen ions through the oxide body, the current density of which is denoted as $\mathbf{j}$ o,ox, where "ox" again means that the current goes through the oxide body, and the local value of $\mathbf{j}$ o,ox at the metal/oxide interface is denoted as $\left.\mathbf{j}_{o, o x}\right|_{m / o}$, while that at the oxide/electrolyte interface is denoted as $\left.\mathbf{j}_{o, o x}\right|_{o / e}$. In turn $\left.\mathbf{j}_{o, o x}\right|_{o / e}$ is contributed by two sources of oxygen ions: one is from water decomposition at the oxide/electrolyte interface ${ }^{167}$

$$
\mathrm{H}_{2} \mathrm{O}_{(\mathrm{aq})} \rightarrow 2 \mathrm{H}_{(\mathrm{aq})}^{+}+\mathrm{O}_{(\mathrm{ox})}^{2-} \text {. }
$$

the current density of which is denoted as $\mathbf{j} o$,o/e, and the other source is from decomposition of old oxide at the oxide/electrolyte interface by reaction R3, the current density of which is $\mathbf{j}$ o,dis which is equal to $\mathbf{j}_{\text {Al,dis }}$ (Eq. (12)). Thus,

$$
\left.\mathbf{j}_{O, o x}\right|_{o / e}=\mathbf{j}_{O, o / e}+\mathbf{j}_{O, d i s} .
$$

As stated before, after oxide decomposition according to $\mathrm{R} 3$, the product aluminum ions will jump across the oxide/electrolyte interface to enter the electrolyte, while the oxygen ions will not cross that potential barrier but will migrate towards the metal/oxide interface by some easy paths. Thus, only those oxygen ions coming from water decomposition (with current density $\mathbf{j}$ o,o/e from R5) need to jump across the potential barrier at the oxide/electrolyte interface, and this current density should also 
follow the Cabrera-Mott equation. ${ }^{128}$ By neglecting the backward current density which is small, $\mathbf{j}$ oo/e is given as

$\mathbf{j}_{O, o / e}=n_{O} A_{O} \exp \left(k_{O} E_{o / e}\right) \hat{\mathbf{E}}_{o / e}$,

where $A_{O}=q_{O} v_{O} \exp \left(-W_{O} / k T\right)$ and $k_{O}=\alpha_{O} q_{O} a_{O} / k T$, and the parameters in these expressions have similar meanings as in Eq. (2.14) albeit now for oxygen ions. From Eqs. (15) and (16), the total ion current density which will go across the oxide/electrolyte interface is

$\mathbf{j}_{\text {total,o/e }}=\mathbf{j}_{\text {Al,o/e }}+\mathbf{j}_{\text {o,ole }}=\left[n_{A l} A_{A l} \exp \left(k_{A l} E_{\text {ole }}\right)+n_{O} A_{O} \exp \left(k_{O} E_{\text {ole }}\right)\right] \hat{\mathbf{E}}_{\text {o/e }}$.

It should be emphasized that in the present model, the oxide body is assumed to be the channel for ion migration, and ions are assumed not able to accumulate or be neutralized. As mentioned above, we also assume that the jump of ions across the oxide/electrolyte interface is the rate determining step for their entire migration across the oxide body, where the oxygen and aluminum ions are weakly bound under the effect of the high electric field, in accordance with O'Sullivan and Wood's electric-field assisted dissolution theory. ${ }^{94}$

\subsubsection{Relationship between aluminum ion current density and oxygen ion current density within the oxide body}

According to the discussion in Sec. 3.2.1 and Sec. 3.2.2, continuous growth of porous alumina depends on the outward migration of aluminum ions (with current density $\mathbf{j}_{A l, o x}$ ) and inward migration of oxygen ions (with current density $\mathbf{j}$ o,ox ) across the oxide barrier layer. We propose that these two current densities should have a fixed relationship because of the following reason. During anodization, many experiments have proven that the metal substrate and the oxide barrier layer are in good contact with each other, ${ }^{94}$ although the theoretical volume expansion ratio (the Pilling-Bedworth ratio) ${ }^{133,137,138}$ equals to 1.7 at the metal/oxide interface. This implies that the oxygen ions must be provided with enough spaces at the metal/oxide interface to form new oxide without influencing the close contact between metal and oxide. These spaces can only be due to the ejected aluminum ions from the metal/oxide interface which will migrate across the oxide barrier layer. As the volume expansion accompanying the oxidation reaction at the metal/oxide interface is fixed under a certain anodization condition, the required spaces to accommodate such volume expansion for maintaining good metal-oxide contact is then fixed, and so the ratio between the outward amount of aluminum ion current density and the inward amount of oxygen ion current density,

$$
\beta=\frac{\left.j_{A l, o x}\right|_{m / o}}{\left.j_{o, o x}\right|_{m / o}}=\frac{\left.j_{A l, o x}\right|_{o / e}}{\left.j_{O, o x}\right|_{o / e}},
$$

should also be fixed during anodization, where $\left.j_{A l, o x}\right|_{m / o}=\left|\mathbf{j}_{A l, o x}\right|_{m / o}\left|, j_{o, o x}\right|_{m / o}=\left|\mathbf{j}_{o, o x}\right|_{m / o} \mid$, $\left.j_{A l, o x}\right|_{o / e}=\left|\mathbf{j}_{A l, o x}\right|_{o / e} \mid$, and $\left.j_{o, o x}\right|_{o / e}=\left|\mathbf{j}_{o, o x}\right|_{o / e} \mid$. In Eq. (19), "ox" means that the corresponding ions migrate across the oxide, and $\left.\right|_{m / o}$ and $\left.\right|_{o / e}$ mean that the values of the corresponding 
current densities are at the metal/oxide or oxide/electrolyte interfaces, respectively. In achieving the second step in Eq. (19), a special case of Eq. (10), namely,

$$
\left.j_{, o x}\right|_{m / o}=\left.j_{, o x}\right|_{o / e} \frac{E_{m / o}}{E_{o / e}}
$$

which links the current densities $\mathbf{j}, o x \mid m / o$ and $\mathbf{j},\left.o x\right|_{o / e}$ at two points on the metal/oxide and oxide/electrolyte interfaces connected by the same electric-field line, is used for both ion species, noting that the electric-field intensities at the two points $E_{m / o}=\left|\mathbf{E}_{m / o}\right|$ and $E_{o / e}=$ $\left|\mathbf{E}_{\text {o/e }}\right|$ are common for both species. From Eqs. (12), (13), (16) and (19), and noting that $\left.\mathbf{j}_{A l, o x}\right|_{o / e},\left.\mathbf{j}_{o, o x}\right|_{o / e}, \mathbf{j}_{A l, o / e}, \mathbf{j}_{o, o / e}, \mathbf{j}_{A l, d i s}$, and $\mathbf{j}_{\text {o,dis }}$ have the same direction $\hat{\mathbf{E}}_{o / e}$ at a given point on the oxide/electrolyte interface,

$\mathbf{j}_{A l, d i s}=\frac{j_{A l, o / e}-\beta j_{O, o / e}}{1+\beta} \hat{\mathbf{E}}_{o / e}$,

where $j_{A l \text {,dis }}=\left|\mathbf{j}_{A l \text {,dis }}\right|$. Strictly speaking, under different anodization conditions such as voltage, electrolyte type, concentration, or substrate grain orientation, $\beta$ may change a little because the volume expansion ratio may change, but the change is expected to be small as the oxide density is usually around $3 \mathrm{~g} / \mathrm{cm}^{3}$ from experiments. ${ }^{4}{ }^{468}$ As a typical condition, we set $\beta$ to be $3 / 7$ in accordance with Siejka and Ortega's experimental results. ${ }^{162}$ It should also be noted that the $\beta$ defined in Eq. (19) is not the same as the current efficiency $\mu=j_{o, o / e} /\left(j_{o, o / e}+j_{A l, o / e}\right)$, and so a constant $\beta$ does not mean that the current efficiency is also a constant.

\subsection{Interface movement equations}

From Faraday's law, ${ }^{1}$ the change in volume $V$ of the oxide caused by a passed charge $Q$ carried by ions is

$V=\frac{M Q}{z F \rho}=\frac{M A j t}{z F \rho}$,

where $M$ is the molecular weight of oxide $\mathrm{Al}_{x} \mathrm{O}_{y}, z=x y, \rho$ is the oxide density, $j$ is the amount of current density corresponding to the reaction, $A$ is the area of oxide surface, $t$ is time and $F$ is Faraday's constant. Since the oxide thickness is given by $D=V / A$, the moving velocity $\mathbf{v}$ of a given point at the interface is proportional to the current density as

$$
\mathbf{v}=-\frac{d D}{d t} \hat{\mathbf{E}}=-\frac{M}{z F \rho} j \hat{\mathbf{E}}
$$

where $\hat{\mathbf{E}}=\mathbf{E} / E$ is the unit vector of the electric field at that given point on the interface. Eq. (23) is not only suitable for the metal/oxide interface where the oxidation reaction R4 takes place but is also suitable for the oxide/electrolyte interface movement where the oxide decomposition reaction $\mathrm{R} 3$ takes place. The moving velocity direction is in the opposite direction of the electric field at a given point on the interface. More specifically, at the oxide/electrolyte interface, the interface movement velocity is $\mathbf{v}_{\text {o/e }}=-\mathbf{j}_{A l \text {,dis }} M / z F \rho$, 
and substituting in Eq. (21), and replacing $\mathbf{j}_{A l, o / e}$ and $\mathbf{j}$ o,o/e by Eqs. (15) and (17), respectively, we obtain

$$
\mathbf{v}_{o / e}=-\frac{M}{z F \rho(1+\beta)}\left[n_{A l} A_{A l} \exp \left(k_{A l} E_{o / e}\right)-\beta n_{o} A_{o} \exp \left(k_{o} E_{o / e}\right)\right] \hat{\mathbf{E}}_{o / e} .
$$

Similarly, the metal/oxide interface movement velocity is $\mathbf{v}_{m / o}=-\left.\mathbf{j}_{o, o x}\right|_{m / o} M / z F \rho$, and from Eqs. (12), (16), (15), (17), (20) and (21), this is given as

$$
\mathbf{v}_{m / o}=-\frac{M}{z F \rho(1+\beta)} \frac{E_{m / o}}{E_{o / e}}\left[n_{A l} A_{A l} \exp \left(k_{A l} E_{o / e}\right)+n_{O} A_{O} \exp \left(k_{O} E_{o / e}\right)\right] \hat{\mathbf{E}}_{m / o} .
$$

where $\hat{\mathbf{E}}_{m / o}=\mathbf{E}_{m / o} / E_{m / o}$. In Eq. (25), as in Eq. (20), the two electric-field intensities $E_{m / o}$ and $E_{o / e}$ are those at two points on the metal/oxide and oxide/electrolyte interfaces connected by a given electric-field line. It should also be noted that, although Eq. (25) is for the velocity of the metal/oxide interface, the present formalism is such that the parameters $n_{A l}, n_{O}, A_{A l}, A_{O}, k_{A l}$ and $k_{O}$ all refer the oxide/electrolyte interface where the rate-determining energy barrier exists.

The density of mobile ions $n_{A l}$ and $n_{O}$ on the oxide/electrolyte interface should depend on the electric field. For instance, from pulse experiments, ${ }^{4}$ the relative change of the mobile ion density depends exponentially on the electric-field intensity by a factor less than 10. A cutoff electric-field intensity $E_{\text {cutoff }}=1.1 \mathrm{~V} \mathrm{~nm}^{-1}$ was predicated, above which all ions become mobile, ${ }^{4}$ which means all ions have the possibility to jump over the potential barrier to realize migration according to the Cabrera-Mott equation. ${ }^{1,4,128}$ To reflect such experimental results, here, we set the relative change of the mobile ion density to depend exponentially on the electric-field intensity as

$$
n_{A l}=n_{A l}^{0} \exp \left[\ln (\lambda)-\ln (\lambda) \frac{E_{\text {ole }}}{E_{\text {cutoff }}}\right]
$$

for $\mathrm{Al}^{3+}$ ions, ${ }^{106}$ where $n_{A l}^{0}$ is the number of $\mathrm{Al}^{3+}$ ions when all of them are mobile and $\lambda$ $=0.2$. For $\mathrm{O}^{2-}$ ions the same relationship was used. Other $\lambda$ values, such as 0.1 and 0.5 , has also been checked, but no significant difference was found in the simulation results compared to the case of $\lambda=0.2$, because at the pore bottom the electric field intensity is always around $1 \mathrm{~V} \mathrm{~nm}^{-1}$.

At the oxide/electrolyte interface, Valand and Heusler experimentally established the following relation between the $\mathrm{O}^{2-}$ current density jo,ole and the $\mathrm{Al}^{3+}$ current density $j_{A l, o / e}:{ }^{169}$

$$
\left(\frac{\partial \ln j_{O, o / e}}{\partial \ln j_{A l, o / e}}\right)_{p H}=1.38( \pm 0.14) \text {, }
$$

where the slope 1.38 is independent of the $p H$ of the electrolyte from 0 to 11 . By substituting Eqs. (15) and (17) into Eq. (27), we can set a relationship of $k_{O} / k_{A l}=1.5$ for the simulation. 
In order to reduce the complexity involved with the number of parameters in the interface movement equations of Eqs. (24) and (25), we adopt the following reduced parameters in our model:

$$
\begin{aligned}
& B_{A l}=n_{A l}^{0} A_{A l}=n_{A l}^{0} C_{H^{+}}^{\eta} q_{A l} v_{A l} \exp \left(-W_{A l} / k T\right), \\
& B_{O}=n_{O}^{0} A_{O}=n_{O}^{0} q_{O} v_{O} \exp \left(-W_{O} / k T\right) .
\end{aligned}
$$

By substituting in Eqs. (26-29), Eqs. (24) and (25) become

$$
\begin{aligned}
\mathbf{v}_{o / e}= & -\frac{M}{z F \rho(1+\beta)} \exp \left[\ln (\lambda)-\ln (\lambda) \frac{E_{\text {ole }}}{E_{\text {cutoff }}}\right] \times \\
& {\left[B_{A l} \exp \left(k_{A l} E_{o / e}\right)-\beta B_{O} \exp \left(k_{O} E_{o / e}\right)\right] \hat{\mathbf{E}}_{o / e}, } \\
\mathbf{v}_{m / o}= & -\frac{M}{z F \rho(1+\beta)} \frac{E_{m / o}}{E_{o / e}} \exp \left[\ln (\lambda)-\ln (\lambda) \frac{E_{o / e}}{E_{\text {cutoff }}}\right] \times \\
& {\left[B_{A l} \exp \left(k_{A l} E_{o / e}\right)+B_{O} \exp \left(k_{O} E_{o / e}\right)\right] \hat{\mathbf{E}}_{m / o} . }
\end{aligned}
$$

The values of $B_{A l}$ and $B_{O}$ were estimated based on each of the parameters involved, which can produce an oxide growth rate on the order of $1 \mathrm{~nm} \mathrm{~s}^{-1}$ at the pore bottom as is commonly observed in mild anodization experiments. ${ }^{92,93}$ For instance, $B_{A l}$ and $B_{O}$ can be set within the ranges of $[0.12,1.5] \mathrm{A} \mathrm{m}^{-2}$ and $[0.024,0.12] \mathrm{A} \mathrm{m}^{-2}$, respectively. An example value of $B_{A l}=1 \mathrm{~A} \mathrm{~m}^{-2}$ can be obtained by using physically reasonable values for the various parameters, ${ }^{4}$ such as charge density $n_{A l}^{0} q_{A l}=1800 \mathrm{C}$ $\mathrm{cm}^{-3}$, vibration frequency $v=10^{12} \mathrm{~s}^{-1}$, temperature $T=275 \mathrm{~K}, p H=1, \eta=1$ and potential barrier $W_{A l}=1.105 \mathrm{eV}$.

\section{Simulation results and discussion}

The above model has been numerically realized by the finite element method to simulate the real-time evolution of pore growth during anodization. ${ }^{170}$ Although the model may be applicable for three-dimensional simulations, for the sake of computational simplicity, only two-dimensional (2-D) simulations corresponding the cross-sectional views of pore channels were conducted. ${ }^{106,136}$ The pore channels start to grow from a prepatterned configuration, in which small concavities have already existed on the alumina surface. These concavities may represent the defects on the sample surface. Also, according to the simulations as well as experiments, pre-patterns cannot determine the final configuration of AAO after enough anodization time when the self-organization condition has been established, after which the configuration is controlled by the anodization conditions or simulation parameters. ${ }^{106,136}$ Details of the simulation results and experimental comparisons have been reported elsewhere, ${ }^{102,106,136}$ and here, we just provide some typical examples. 

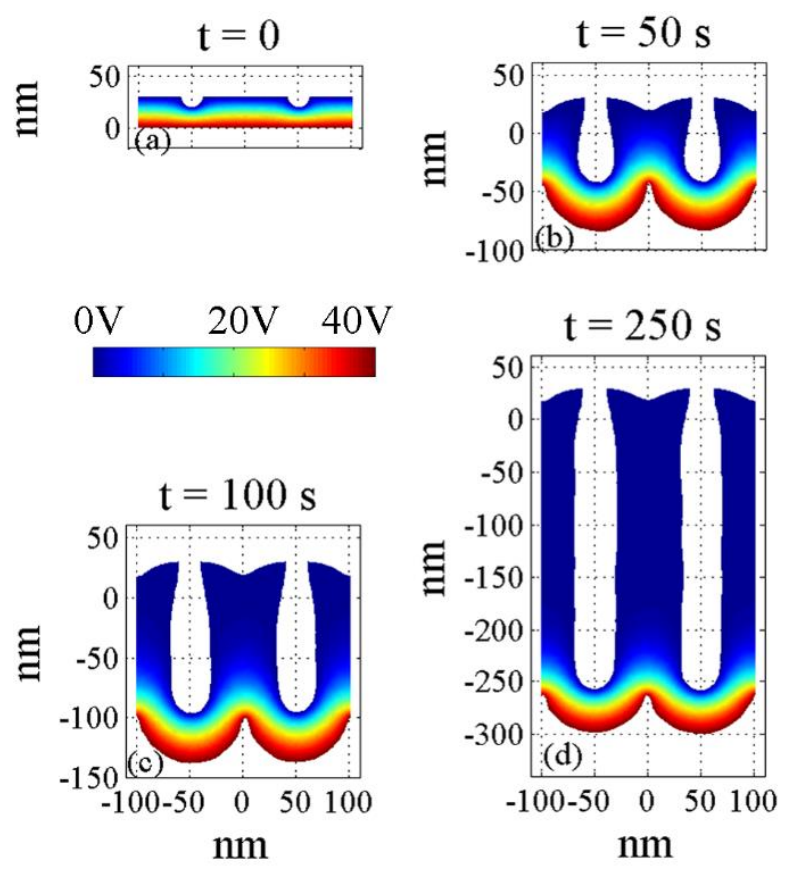

Figure 4. Simulated growth process of porous structure in AAO, starting from a prepatterned initial configuration at $t=0$ with an initial barrier layer thickness $20 \mathrm{~nm}$. The simulation parameters are $40 \mathrm{~V} ; B_{O}=0.072 \mathrm{~A} \mathrm{~m}^{-2} ; B_{A l}=0.72 \mathrm{~A} \mathrm{~m}^{-2}, k_{O} / k_{A 1}=1.5 ; k_{O}=3.8$ $\mathrm{nm} \mathrm{V} \mathrm{V}^{-1} ; \beta=3 / 7$. The simulated porous structures at anodization time points of $t=50 \mathrm{~s}$, $100 \mathrm{~s}$ and $250 \mathrm{~s}$ are shown. (Adapted from Ref. 170.)

Figure 4 shows how two small initial cavities in a pre-patterned alumina surface will evolve into steady-state U-shaped pore channels. At the anodizaiton time $t=0$, the initial configuration has two concavities with diameter $20 \mathrm{~nm}$. The interpore distance is $200 \mathrm{~nm}$, satisfying the stable interpore distance to voltage ratio of $\sim 2.5 \mathrm{~nm} \mathrm{~V}^{-1}$ typically found in mild anodization experiments. ${ }^{92,93}$ The barrier layer is flat along the oxide/metal interface, and has a thickness of $20 \mathrm{~nm}$ at the pore bottom region. Because of the Neumann boundary condition in Eq. (4) for the left and right edges of the sample, the present simulation represents an infinite series of repeating units. The simulation parameters are listed in the caption of Fig. 4.

With time increased to $50 \mathrm{~s}$ in Fig. 4, the oxide growth accelerates around the pore bottom regions, due to the concentrated electric-potential distribution there which gives rise to much higher electric-field intensity compared to the pore walls and the top surface of the sample. The initial pores develop into water-drop shaped pore channels, which were typically observed in experiments at the beginning of anodization, appears. Also, a scallop-shape of the oxide barrier layer frequently observed in experiments ${ }^{171,172}$ is formed from $t=50 \mathrm{~s}$ onward. ${ }^{171,172}$ With time increased to $250 \mathrm{~s}$, U-shaped pore channels corresponding to the usual steady-state configuration of AAO are developed. From Eqs. (30) and (31), the interface velocity exponentially depends on the electric field along the interface. In a domain with finger-like features connected by a thin common base the Laplacian electric-potential distribution has to exhibit concentrated potential drop within the base region, and this leads to the faster oxide growth rate at the bottom 
of the pores driven by the electric field. In addition, from the steady-state configuration in Fig. 4, the average barrier layer thickness along the two pore axes is $41.7 \mathrm{~nm}$, which is in accordance with the stable barrier-layer thickness-to-voltage ratio of $\sim 1 \mathrm{~nm} \mathrm{~V}^{-1}$ found in experiments. ${ }^{92,172,173}$
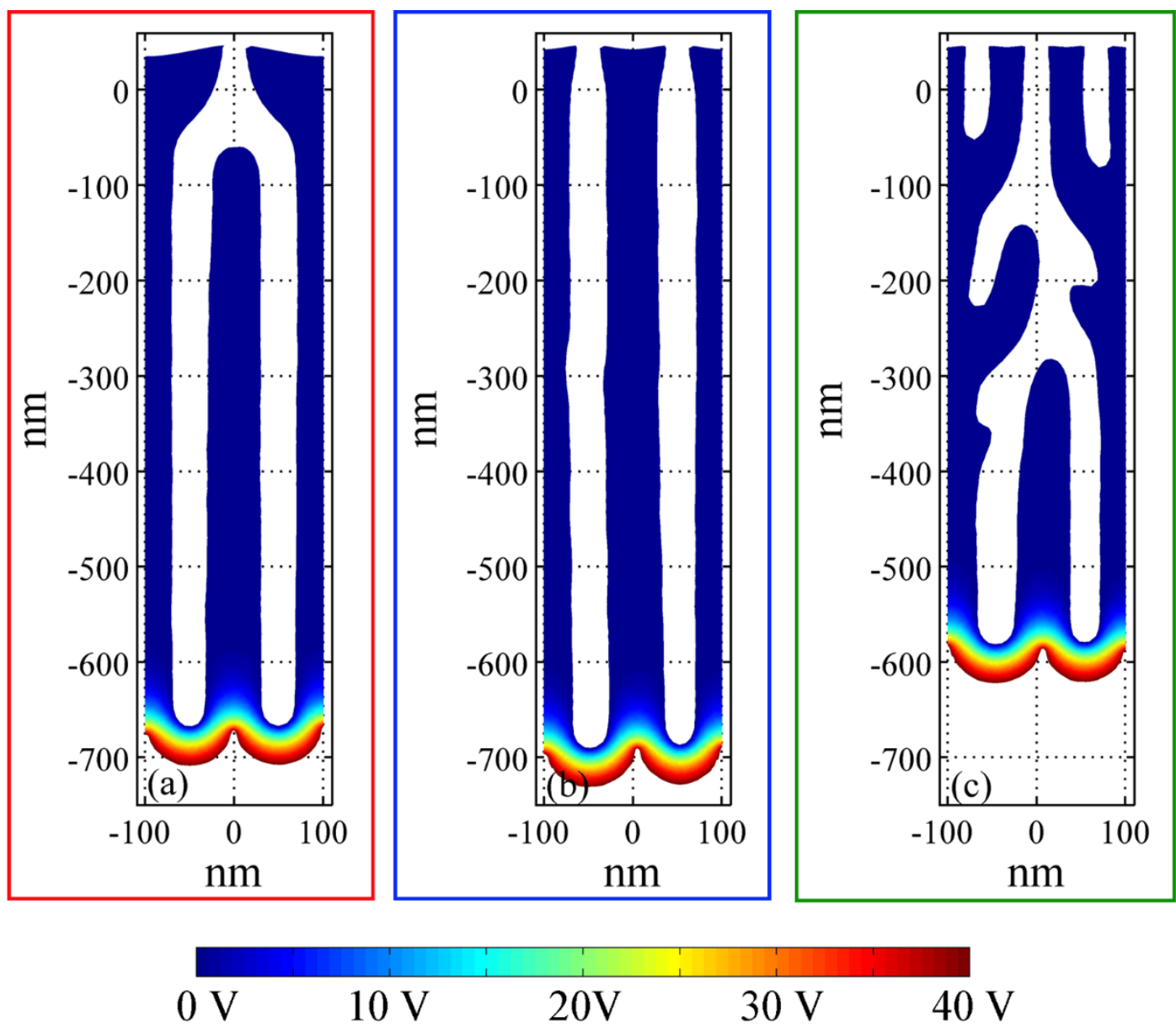

Figure 5. AAO porous structures after $700 \mathrm{~s}$ anodization time. The simulation cell initially contains (a) 1 initial pore; (b) 2 initial pores; (c) 3 initial pores. Each initial configuration is centro-symmetric. Except the number of initial pores, the initial pore dimensions, as well as anodization conditions (voltage, $B_{A l}$ and $B_{O}$ ), are the same as in Fig. 4 (40 V; $\left.B_{O}=0.072 \mathrm{~A} \mathrm{~m}^{-2} ; B_{A l}=0.72 \mathrm{~A} \mathrm{~m}^{-2}, k_{O} / k_{A 1}=1.5 ; k_{O}=3.8 \mathrm{~nm} \mathrm{~V}^{-1} ; \beta=3 / 7\right)$. (Adapted from Ref. 106.)

Fig. 5 shows the results of another set of simulations which were different from Fig. 4 in terms of the initial configurations, but the same in terms of other simulation parameters. Among the three initial configurations simulated, only that in Fig. 5(b) has the initial interpore distance-to-voltage ratio satisfied the $2.5 \mathrm{~nm} \mathrm{~V}^{-1}$ self-ordering condition found in mild anodization experiments. ${ }^{92,93}$ In Figs. 5(a) and 5(c), the initial interpore distance-to-voltage ratio are 5.0 and 1.7, respectively. In Fig. 5(b), stable growth of the pore channels takes place, with the initial interpore distance-to-voltage 
ratio maintained, at all times within the simulation. However, for both Figs. 5(a) and 5(c), the growth of the pore channels is unstable, with branching of the single pore happening in the former, and termination of two of the three pores in latter. However, selforganization takes place, and after an enough long anodization time (here, $700 \mathrm{~s}$ ), , the final configurations of both Figs. 5(a) and 5(c) reach to the same interpore distance-tovoltage ratio as in Fig. 5(b). This indicates that the final configuration of pore channels does not depend on the initial configuration, but is determined by the simulation parameters, which have been set the same for these three simulations. Fig. 5 also confirms that our simulation can reproduce the typical experimental result of interpore distance-to-voltage ratio of $\sim 2.5 \mathrm{~nm} \mathrm{~V}^{-1}$.

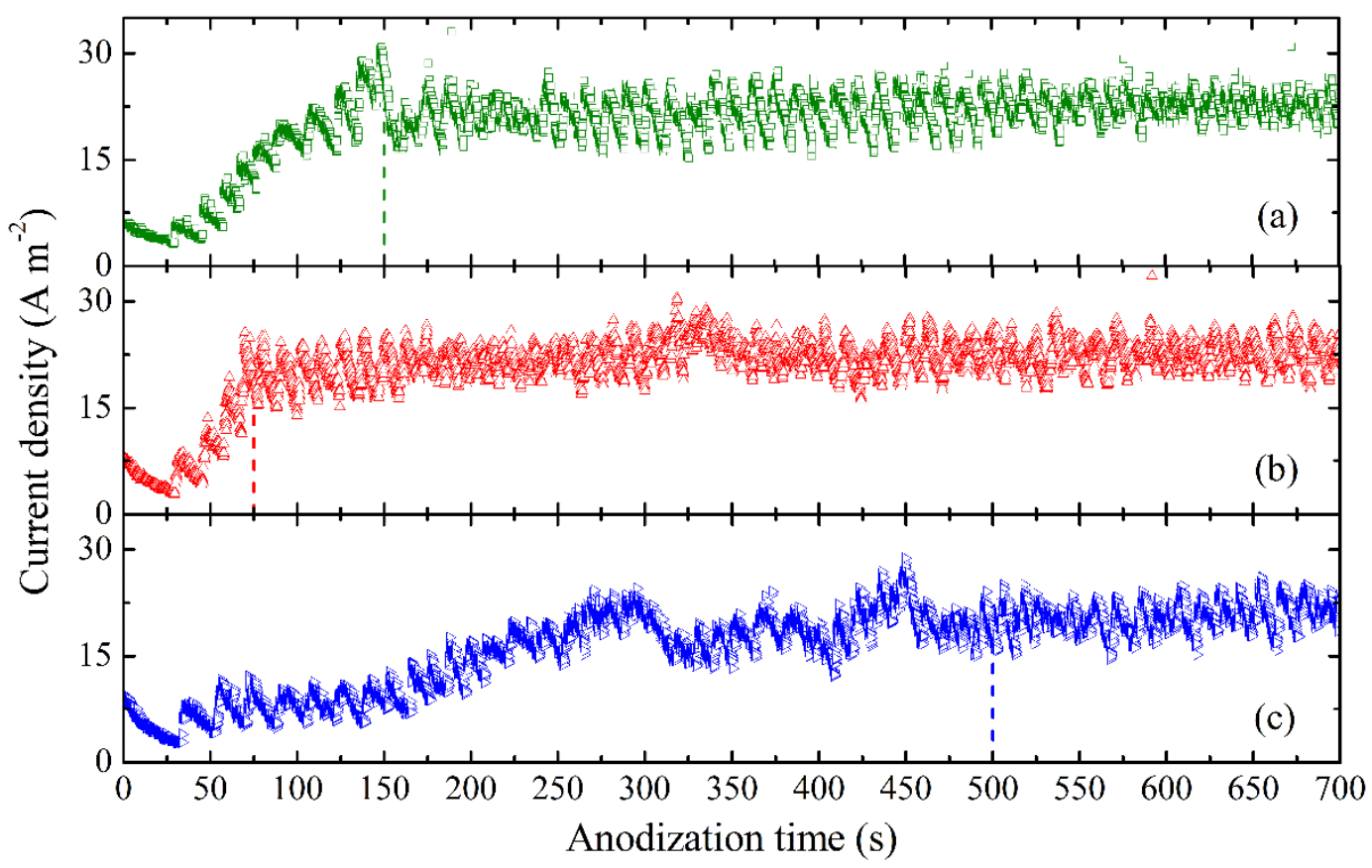

Figure 6. Plot of current density against time corresponding to the anodization process with (a) 1 initial pore in Fig. 5 (a); (b) 2 initial pores in Fig. 5 (b); (c) 3 initial pores in Fig. 5 (c). (Adapted from Ref. 106.)

Figure 6 shows the current density against time relationship corresponding to the pore channel growth process in Fig. 5. The evolution trend is much similar to the illustration in Fig. 2. However, for the case of two initial pores in Fig. 6(b), much shorter time of $\sim 75 \mathrm{~s}$ is required to reach the steady-state current density $\left(\sim 20 \mathrm{~A} \mathrm{~m}^{-2}\right)$ compared to the other two cases. Due to the incommensurate interpore spacing in the pre-pattern with the applied voltage, the case with one initial pore takes $\sim 150$ s and that with three initial pores takes $\sim 500 \mathrm{~s}$ to reach the steady state. In experiments, for instance, if a prepattern has already been formed by a first-step anodization, then during a second-step anodization the current density needs less time to reach steady state than the first anodization process. ${ }^{133,174}$

It should be noted that the simulation parameters used in both Figs. 4 and 5 are located within a window in which stable, self-ordered pore growth always occurs. ${ }^{106}$ If 
the parameters are selected from outside this window, then, as shown in our previous reports, ${ }^{106}$ the pore-channels cannot maintain straight, but frequently branch or terminate during their growth. This window of simulation parameters corresponding to stable pore growth should correspond to the experimentally established window of processing conditions under which self-ordered AAO formation occurs.

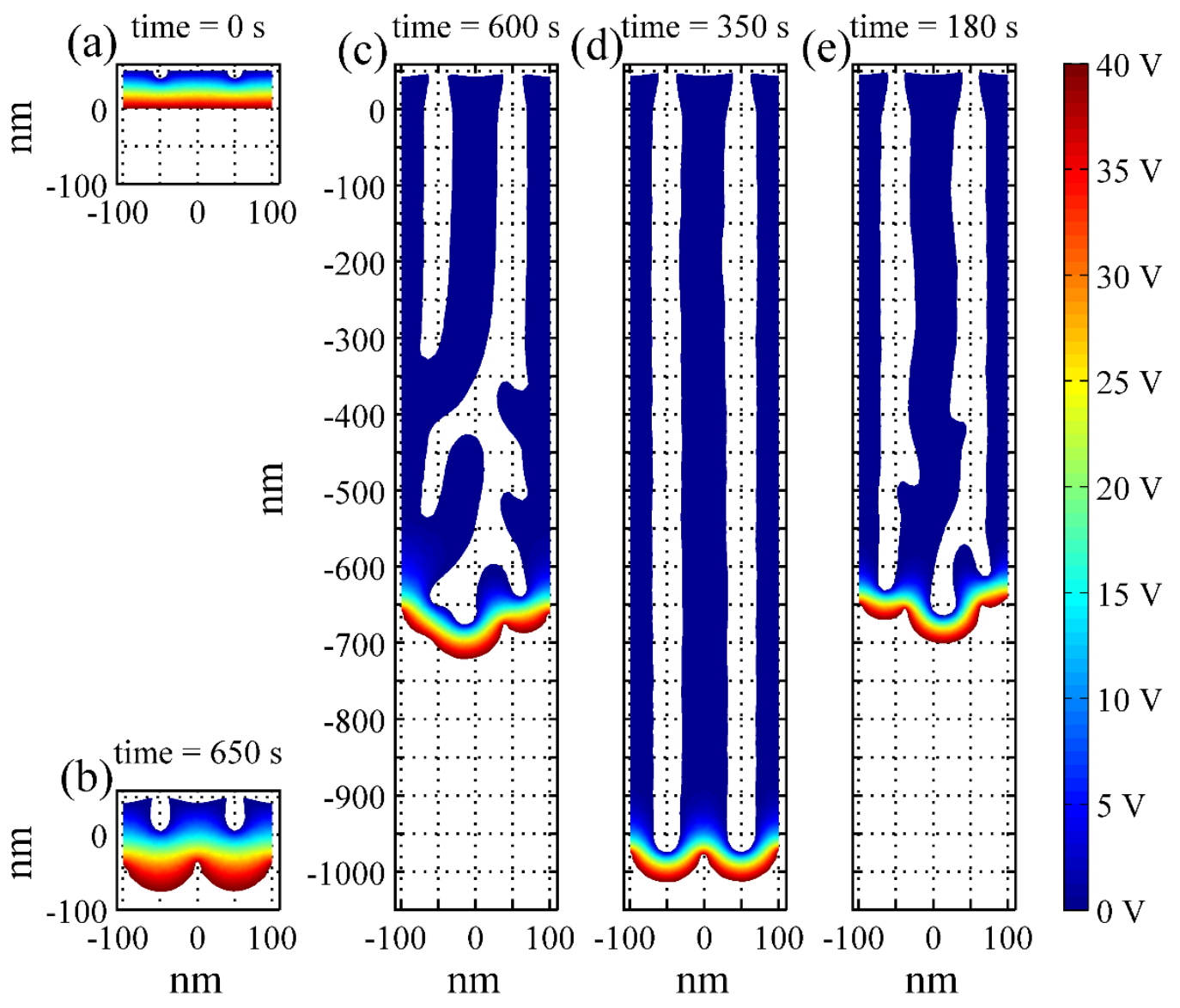

Figure 7. Simulation of pore channel growth in AAO starting from (a) the same initial configuration ( $(t=0 \mathrm{~s})$, but under different values of $B_{A l}\left(\propto C_{H^{+}}\right)$: (b) 0.3, (c) 0.96, (d) 1.32 , and (e) $1.56 \mathrm{~A} \mathrm{~m}^{-2}$. Other parameters are kept the same $\left(40 \mathrm{~V}, B_{O}=0.096 \mathrm{~A} \mathrm{~m}^{-2}\right.$, $k_{O} / k_{A l}=1.5, k_{O}=4.2 \mathrm{~nm} \mathrm{~V}^{-1}, \beta=3 / 7$ ). (Adapted from Ref. 136.)

For instance, Fig. 7 shows how the same initial configuration (Fig. 7 (a)) can develop in different stable or unstable manners under different values of $B_{A l,}$. From Figs. 7(b) to 7(e), by increasing $B_{A l}$, only, the configuration at prolonged simulation times can vary from a barrier type in Fig. 7(b), to an unstable porous structure in Fig. 7(c), stable structure in Fig. 7(d), and back to unstable porous structure in Fig.7(e). From Eq. (28), $B_{A l}$ is proportional to the $\mathrm{H}^{+}$concentration $C_{H^{+}}$in the electrolyte. For comparison with experiments, therefore, we can regard the change of $B_{A l}$ as only due to the change of $C_{H^{+}}$, 
which can be easily varied in experiments by controlling the acid concentration. Good agreements between the simulation results in Fig. 7 and experimental results by changing acid concentration only have been demonstrated, the details of which can be found in our previous report. ${ }^{136}$

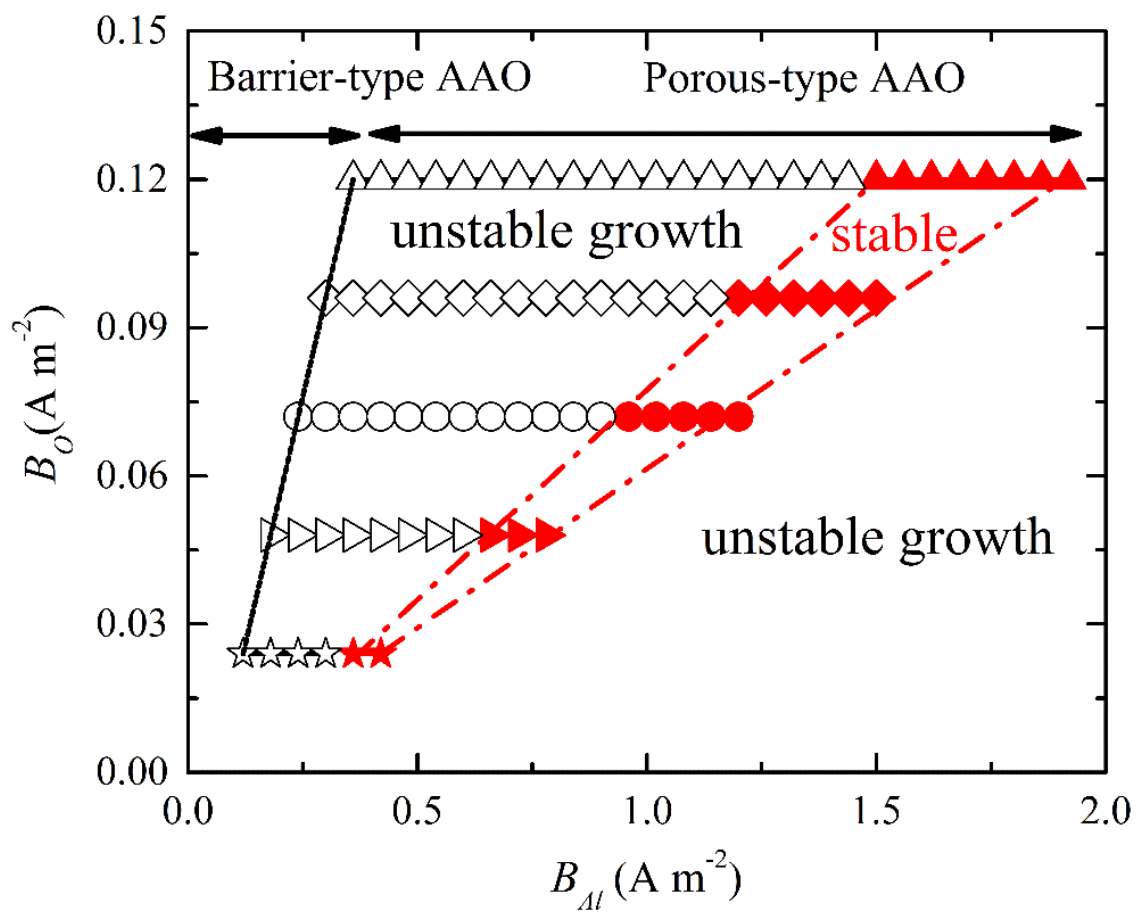

Figure 8. Map of $B_{O}$ and $B_{A l}$ conditions for different types of nanoporous alumina structures to occur. ( $40 \mathrm{~V}, k_{O} / k_{A l}=1.5, k_{O}=4.2 \mathrm{~nm} \mathrm{~V}^{-1}, \beta=3 / 7$ ) (Adapted from Ref. 136.)

The situation depicted in Fig. 7 is only one typical trend with $B_{A l}$ increasing, as shown in Fig. 8. By varying both $B_{O}$ and $B_{A l}$ while keeping other simulation parameters the same as Fig. 6, a map is plotted which shows the growth stability of the same initial porous structure under different parameter values. Fig. 8 shows that, under a certain $B_{O}$ value, the structural transformation trend is from barrier-type to unstable porous to stable porous and unstable porous again with $B_{A l}$ increasing. Fig. 8 indicates that the stable pore growth region is very narrow, and this explains why the experimental processing window for self ordering is very narrow. ${ }^{91-93}$

\section{Outlook}

In the model presented in Sec. 3, space charge within the AAO body and the double-layer effects along both the oxide/electrolyte and metal/oxide interfaces have been neglected. If space charge is considered, the Poisson equation for electric-field distribution in AAO should be used. The question is how the space charge can distribute within AAO. In addition, volume expansion during oxidation reaction may produce a significant compression stress at the oxide barrier layer. To incorporate the effects of the stress field into the current electric-field based model may be an important step that 
would end the current debate in terms of the driving force. Furthermore, in real cases, due to the contamination of electrolyte ions within the outside layer of the AAO pore channels, both electric-potential distribution and oxide density may vary. A complete model should also consider the electrolyte type dependent effects. The above factors may be correlated with each other and require future investigations.

\section{Conclusions}

Different growth mechanisms for nanoporous alumina have been reviewed. In terms of driving force, the previous models may be summarized into two groups, namely, electric-field assisted, and mechanical-stress induced mechanisms. A kinetics model recently developed by the authors has been presented. In our model, pore growth is driven by electric-field assisted oxide decomposition at the oxide/electrolyte interface and oxide formation at the metal/oxide interface. Numerical simulation of two-dimensional pore-channel growth in nanoporous alumina with pre-patterned initial configurations has been performed by the finite element method. To the best of our knowledge, this is the first successful attempt to numerically simulate the real-time evolution process of porous alumina growth, starting from non-steady-state initial porous configurations to reach steady-state configurations. This model can capture typical features observed in experiments including pore-channel growth and self-organization processes towards ordering, which supports that electric field can be the key driving force for pore growth in nanoporous alumina.

\section{Acknowledgment}

The work described here was funded by a grant from the Research Grants Council of the Hong Kong Special Administrative Government, P.R. China (project code: 17206114).

\section{References}

${ }^{1}$ J. W. Diggle, T. C. Downie, and C. W. Goulding, Chem. Rev. 69, 365 (1969).

${ }^{2}$ G. C. Wood, in Oxide and Oxide Films; Vol. 2, edited by J. W. Diggle (Marcel Dekker, New York, 1973), p. 167.

${ }^{3}$ G. E. Thompson and G. C. Wood, in Treatise on Materials Science and Technology; Vol. 23, edited by J. C. Scully (Academic Press, New York, 1983), p. 205.

${ }^{4}$ M. M. Lohrengel, Mater. Sci. Eng., R 11, 243 (1993).

${ }^{5}$ H. Chik and J. M. Xu, Mater. Sci. Eng. R 43, 103 (2004).

${ }^{6}$ B. Sakintuna and Y. Yurum, Ind. Eng. Chem. Res. 44, 2893 (2005).

${ }^{7}$ H. T. Wang and J. F. Yao, Ind. Eng. Chem. Res. 45, 6393 (2006).

${ }^{8}$ F. Cheng, Z. Tao, J. Liang, and J. Chen, Chem. Mater. 20, 667 (2008).

${ }^{9}$ C. Bae, H. Yoo, S. Kim, K. Lee, J. Kim, M. A. Sung, and H. Shin, Chem. Mater. 20, 756 (2008).

${ }^{10}$ Y. Lei, S. K. Yang, M. H. Wu, and G. Wilde, Chem. Soc. Rev. 40, 1247 (2011).

${ }^{11}$ K. Okada, T. Isobe, K. Katsumata, Y. Kameshima, A. Nakajima, and K. J. D. MacKenzie, Sci.

Technol. Adv. Mater. 12 (2011).

${ }^{12}$ H. M. Chen and R. S. Liu, J. Phys. Chem. C 115, 3513 (2011).

${ }^{13}$ B. Platschek, A. Keilbach, and T. Bein, Adv. Mater. 23, 2395 (2011). 
${ }^{14}$ A. de la Escosura-Muniz and A. Merkoci, ACS Nano 6, 7556 (2012).

${ }^{15}$ Q. Hao, T. Qiu, and P. K. Chu, Prog. Surf. Sci. 87, 23 (2012).

${ }^{16}$ C. J. Ingham, J. ter Maat, and W. M. de Vos, Biotechnol. Adv. 30, 1089 (2012).

${ }^{17}$ J. Martin, J. Maiz, J. Sacristan, and C. Mijangos, Polymer 53, 1149 (2012).

${ }^{18}$ C. Nicolini, N. Bragazzi, and E. Pechkova, Adv. Drug. Delivery Rev. 64, 1522 (2012).

${ }^{19}$ C. R. Simovski, P. A. Belov, A. V. Atrashchenko, and Y. S. Kivshar, Adv. Mater. 24, 4229

(2012).

${ }^{20}$ J. T. Zhang and C. M. Li, Chem. Soc. Rev. 41, 7016 (2012).

${ }^{21}$ M. E. Warkiani, A. A. S. Bhagat, B. L. Khoo, J. Han, C. T. Lim, H. Q. Gong, and A. G. Fane, ACS Nano 7, 1882 (2013).

${ }^{22}$ G. Tai, K. Wang, Z. Sun, J. Yin, S. M. Ng, J. Zhou, F. Yan, C. W. Leung, K. H. Wong, W. Guo, and e. al., J. Phys. Chem. C 116, 532 (2012).

${ }^{23}$ T. Kondo, H. Masuda, and K. Nishio, J. Phys. Chem. C 117, 2531 (2013).

${ }^{24}$ M. H. Wu, L. Y. Wen, Y. Lei, S. Ostendorp, K. Chen, and G. Wilde, Small 6, 695 (2010).

${ }^{25}$ X. Y. Zhang, G. H. Wen, Y. F. Chan, R. K. Zheng, X. X. Zhang, and N. Wang, Appl. Phys. Lett. 83, 3341 (2003).

${ }^{26}$ D. Borissov, S. Isik-Uppenkamp, and M. Rohwerder, J. Phys. Chem. C 113, 3133 (2009).

${ }^{27}$ K. G. Biswas, H. E. Matbouly, V. Rawat, J. L. Schroeder, and T. D. Sands, Appl. Phys. Lett. 95, 073108 (2009).

${ }^{28}$ X. D. Li, G. W. Meng, Q. L. Xu, M. G. Kong, X. G. Zhu, Z. Q. Chu, and A. P. Li, Nano Lett. 11, 1704 (2011).

${ }^{29}$ J. Kim, H. Han, Y. H. Kim, S. H. Choi, J. C. Kim, and W. Lee, ACS Nano 5, 3222 (2011).

${ }^{30}$ S. L. Sung, S. H. Tsai, S. H. Tseng, F. K. Chiang, X. W. Liu, and H. C. Shih, Appl. Phys. Lett.

74, 197 (1999).

${ }^{31}$ H. Chun, M. G. Hahm, Y. Homma, R. Meritz, K. Kuramochi, L. Menon, L. Ci, P. M. Ajayan, and Y. J. Jung, ACS Nano 3, 1274 (2009).

${ }^{32}$ S. H. Jeong, H. Y. Hwang, K. H. Lee, and Y. Jeong, Appl. Phys. Lett. 78, 2052 (2001).

${ }^{33}$ S. A. Knaack, M. Redden, and M. Onellion, Am. J. Phys. 72, 856 (2004).

${ }^{34}$ J. Zou, X. Qi, L. Tan, and B. J. H. Stadler, Appl. Phys. Lett. 89, 093106 (2006).

${ }^{35}$ S. Hong, T. Kang, D. Choi, Y. Choi, and L. P. Lee, ACS Nano 6, 5803 (2012).

${ }^{36}$ Y. T. Chong, M. Y. E. Yau, Y. Yang, M. Zacharias, D. Gorlitz, K. Nielsch, and J. Bachmann, J. Appl. Phys. 110 (2011).

${ }^{37}$ M. Koohbor, S. Soltanian, M. Najafi, and P. Servati, Mater. Chem. Phys. 131, 728 (2012).

${ }^{38}$ X. W. Wang, Z. H. Yuan, and B. C. Fang, Mater. Chem. Phys. 125, 1 (2011).

${ }^{39}$ T. Kim, L. He, J. R. Morales, W. P. Beyermann, and C. J. Bardeen, Nanotechnology 22 (2011).

${ }^{40} \mathrm{~V}$. Vega, T. Bohnert, S. Martens, M. Waleczek, J. M. Montero-Moreno, D. Gorlitz, V. M. Prida, and K. Nielsch, Nanotechnology 23 (2012).

${ }^{41}$ D. C. Leitao, J. Ventura, C. T. Sousa, A. M. Pereira, J. B. Sousa, M. Vazquez, and J. P. Araujo, Phys. Rev. B 84 (2011).

${ }^{42}$ A. Santos, J. M. Montero-Moreno, J. Bachmann, K. Nielsch, P. Formentin, J. Ferre-Borrull, J. Pallares, and L. F. Marsal, ACS Appl. Mater. Interfaces 3, 1925 (2011).

${ }^{43}$ J. H. Fang, I. Aharonovich, I. Leychenko, K. Ostrikov, P. G. Spizzirri, S. Rubanov, and S.

Prawer, Cryst. Growth Design 12, 2917 (2012).

${ }^{44}$ X. Sheng, J. F. Liu, N. Coronel, A. M. Agarwal, J. Michel, and L. C. Kimerling, IEEE Photo.

Tech. Lett. 22, 1394 (2010).

${ }^{45}$ P. Yan, G. T. Fei, G. L. Shang, B. Wu, and L. D. Zhang, J. Mater. Chem. C 1, 1659 (2013).

${ }^{46}$ Y. Su, G. T. Fei, Y. Zhang, P. Yan, H. Li, G. L. Shang, and L. D. Zhang, Mater. Lett. 65, 2693

(2011).

${ }^{47}$ X. L. Q. Wang, D. X. Zhang, H. J. Zhang, Y. Ma, and J. Z. Jiang, Nanotechnology 22 (2011). 
${ }^{48}$ I. Maksymov, J. Ferre-Borrull, J. Pallares, and L. F. Marsal, Photon. Nanostruc. Fund. Applic. 10, 459 (2012).

${ }^{49}$ A. Sato, Y. Pennec, T. Yanagishita, H. Masuda, W. Knoll, B. Djafari-Rouhani, and G. Fytas, New J. Phys. 14 (2012).

${ }^{50}$ X. D. Li, G. W. Meng, S. Y. Qin, Q. L. Xu, Z. Q. Chu, X. G. Zhu, M. G. Kong, and A. P. Li, ACS Nano 6, 831 (2012).

${ }^{51}$ F. M. Han, G. W. Meng, Q. L. Xu, X. G. Zhu, X. L. Zhao, B. S. Chen, X. D. Li, D. C. Yang, Z. Q. Chu, and M. G. Kong, Angew. Chem. Int. Ed. 50, 2036 (2011).

${ }^{52}$ G. D. Sulka, A. Brzozka, and L. F. Liu, Electrochim. Acta 56, 4972 (2011).

${ }^{53}$ I. E. Rauda, R. Senter, and S. H. Tolbert, J. Mater. Chem. C 1, 1423 (2013).

${ }^{54}$ B. Benfedda, L. Hamadou, N. Benbrahim, A. Kadri, E. Chainet, and F. Charlot, J. Electrochem. Soc. 159, C372 (2012).

${ }^{55}$ M. K. Date, B. C. Chiu, C. H. Liu, Y. Z. Chen, Y. C. Wang, H. Y. Tuan, and Y. L. Chueh, Mater. Chem. Phys. 138, 5 (2013).

${ }^{56}$ W. Liu, X. D. Wang, R. Xu, X. F. Wang, K. F. Cheng, H. L. Ma, F. H. Yang, and J. M. Li, Mater. Sci. Semicond. Proc. 16, 160 (2013).

${ }^{57}$ Y. Xiang, A. Keilbach, L. M. Codinachs, K. Nielsch, G. Abstreiter, A. F. I. Morral, and T. Bein, Nano Lett. 10, 1341 (2010).

${ }^{58}$ S. L. Brock, I. U. Arachchige, and J. L. Mohanan, Science 307, 397 (2005).

${ }^{59}$ M. Tian, W. Wang, Y. J. Wei, and R. G. Yang, J. Power Sour. 211, 46 (2012).

${ }^{60}$ M. Tian, W. Wang, S. H. Lee, Y. C. Lee, and R. G. Yang, J. Power Sour. 196, 10207 (2011).

${ }^{61}$ G. Ferrara, L. Damen, C. Arbizzani, R. Inguanta, S. Piazza, C. Sunseri, and M. Mastragostino, J.

Power Sour. 196, 1469 (2011).

${ }^{62}$ W. Wang, M. Tian, A. Abdulagatov, S. M. George, Y. C. Lee, and R. G. Yang, Nano Lett. 12, 655 (2012).

${ }^{63}$ Y. C. Tsao, T. Sondergaard, E. Skovsen, L. Gurevich, K. Pedersen, and T. G. Pedersen, Opt.

Exp. 21, A84 (2013).

${ }^{64}$ D. Chen, W. Zhao, and T. P. Russell, ACS Nano 6, 1479 (2012).

${ }^{65}$ L. C. Haspert, S. B. Lee, and G. W. Rubloff, ACS Nano 6, 3528 (2012).

${ }^{66}$ T. Xue, X. Wang, and J. M. Lee, J. Power Sour. 201, 382 (2012).

${ }^{67}$ L. J. Li, B. Zhu, S. J. Ding, H. L. Lu, Q. Q. Sun, A. Q. Jiang, D. W. Zhang, and C. X. Zhu, Nanoscale Res. Lett. 7 (2012).

${ }^{68}$ W. Lee, H. Han, A. Lotnyk, M. A. Schubert, S. Senz, M. Alexe, D. Hesse, S. Baik, and U. Gösele, Nat. Nanotechnol. 3, 402 (2008).

${ }^{69}$ J. Jiang, Y. Li, J. Liu, X. Huang, C. Yuan, and X. W. Lou, Adv. Mater. 24, 5166 (2012).

${ }^{70}$ K. Hotta, A. Yamaguchi, and N. Teramae, ACS Nano 6, 1541 (2012).

${ }^{71}$ K. Vasilev, Z. Poh, K. Kant, J. Chan, A. Michelmore, and D. Losic, Biomaterials 31, 532 (2010).

${ }^{72}$ J. B. Li, Y. Yu, X. N. Peng, Z. J. Yang, Z. K. Zhou, and L. Zhou, J. Appl. Phys. 111 (2012).

${ }^{73}$ K. Hotta, A. Yamaguchi, and N. Teramae, J. Phys. Chem. C 116, 23533 (2012).

${ }^{74}$ A. Santos, M. Alba, M. M. Rahman, P. Formentin, J. Ferre-Borrull, J. Pallares, and L. F. Marsal, Nanoscale Res. Lett. 7, 228 (2012).

${ }^{75}$ S. H. Yeom, O. G. Kim, B. H. Kang, K. J. Kim, H. Yuan, D. H. Kwon, H. R. Kim, and S. W. Kang, Opt. Exp. 19, 22882 (2011).

${ }^{76}$ C. Nicolini, T. Bezerra, and E. Pechkova, Nanomedicine 7, 1117 (2012).

${ }^{77}$ J. T. Chen, W. L. Chen, and P. W. Fan, ACS Macro Lett. 1, 41 (2012).

${ }^{78}$ A. Y. Y. Ho, L. P. Yeo, Y. C. Lam, and I. Rodriguez, ACS Nano 5, 1897 (2011).

${ }^{79}$ Y. Wang, L. Tong, and M. Steinhart, Acs Nano 5, 1928 (2011).

${ }^{80}$ T. Yanagishita, R. Fujimura, K. Nishio, and H. Masuda, Chem. Lett. 39, 188 (2010). 
${ }^{81}$ N. Suzuki, M. Imura, Y. Nemoto, X. F. Jiang, and Y. Yamauchi, Crystengcomm 13, 40 (2011).

${ }^{82}$ J. T. Chen, C. W. Lee, M. H. Chi, and I. C. Yao, Macromol. Rap. Comm. 34, 348 (2013).

${ }^{83}$ K. Kwon, C. W. Park, and D. Kim, Sensor. Actuat. A-Phys. 175, 108 (2012).

${ }^{84}$ Y. H. Ma, G. Q. Zhan, M. Ma, X. Wang, and C. Y. Li, Bioelectrochemistry 84, 6 (2012).

${ }^{85}$ J. R. Deneault, X. Y. Xiao, T. S. Kang, J. S. Wang, C. M. Wai, G. J. Brown, and M. F. Durstock, Chemphyschem 13, 256 (2012).

${ }^{86}$ R. M. Michell, A. T. Lorenzo, A. J. Muller, M. C. Lin, H. L. Chen, I. Blaszczyk-Lezak, J.

Martin, and C. Mijangos, Macromolecules 45, 1517 (2012).

${ }^{87}$ Y. Suzuki, H. Duran, M. Steinhart, H. J. Butt, and G. Floudas, Soft Matter 9, 2621 (2013).

${ }^{88}$ H. Wu, Z. H. Su, and A. Takahara, Soft Matter 7, 1868 (2011).

${ }^{89}$ K. Shwirn, W. Lee, R. Hillebrand, M. Steinhart, K. Nielsch, and U. Gösele, ACS Nano 2, 302 (2008).

${ }^{90}$ C. Cheng and A. H. W. Ngan, Nanotechnology 24, 215602 (2013).

${ }^{91}$ C. K. Y. Ng and A. H. W. Ngan, Chem. Mater. 23, 5264 (2011).

${ }^{92}$ W. Lee, R. Ji, U. Gösele, and K. Nielsch, Nat. Mater. 5, 741 (2006).

${ }^{93}$ H. Masuda and K. Fukuda, Science 268, 1466 (1995).

${ }^{94}$ J. P. O'Sullivan and G. C. Wood, Proc. R. Soc. London, Ser. A 317, 511 (1970).

${ }^{95}$ G. E. Thompson and G. C. Wood, Nature 290, 230 (1981).

${ }^{96}$ E. Moyen, L. Santinacci, L. Masson, W. Wulfhekel, and M. Hanbucken, Adv. Mater. 24, 5094 (2012).

${ }^{97}$ F. Keller, M. S. Hunter, and D. L. Robinson, J. Electrochem. Soc. 100, 441 (1953).

${ }^{98}$ N. Q. Zhao, X. X. Jiang, C. S. Shi, J. J. Li, Z. G. Zhao, and X. W. Du, J. Mater. Sci. 42, 3878 (2007).

${ }^{99}$ A. L. Friedman, D. Brittain, and L. Menon, J. Chem. Phys. 127, 154717 (2007).

${ }^{100}$ C. Cheng, K. Y. Ng, and A. H. W. Ngan, AIP Adv. 1, 042113 (2011).

${ }^{101}$ A. P. Li, F. Müller, A. Birner, K. Nielsch, and U. Gosele, J. Vac. Sci. Technol. A 17, 1428 (1999).

${ }^{102}$ C. Cheng, K. Y. Ng, N. R. Aluru, and A. H. W. Ngan, J. Appl. Phys. 113, 204903 (2013).

${ }^{103}$ A. L. Friedman and L. Menon, J. Appl. Phys. 101, 084310 (2007).

${ }^{104}$ H. Masuda, F. Hasegwa, and S. Ono, J. Electrochem. Soc. 144, L127 (1997).

${ }^{105}$ H. Masuda, K. Yada, and A. Osada, Jpn. J. Appl. Phys. 37, L1340 (1998).

${ }^{106}$ C. Cheng and A. H. W. Ngan, Electrochim. Acta 56, 9998 (2011).

${ }^{107}$ S. Anderson, J. Appl. Phys. 15, 477 (1944).

${ }^{108}$ T. P. Hoar and N. F. Mott, J. Phys. Chem. Solids 9, 97 (1959).

${ }^{109}$ T. P. Hoar, in Modern Aspects of Electrochemistry, edited by J. O. M. Bockris (Butterworths Scientific Publications, London, 1959), p. 263.

${ }^{110} \mathrm{~J}$. W. Diggle, in Oxide and Oxide Films; Vol. 2, edited by J. W. Diggle (Marcel Dekker, New York, 1973), p. 281.

${ }^{111}$ G. E. Thompson, R. C. Furneaux, G. C. Wood, J. A. Richardson, and J. S. Goode, Nature 271, 433 (1978).

${ }^{112}$ G. E. Thompson, Thin Solid Films 297, 192 (1997).

${ }^{113}$ V. P. Parkhutik and V. I. Shershulsky, J. Phys. D: Appl. Phys. 25, 1258 (1992).

${ }^{114}$ S. K. Thamida and H. C. Chang, Chaos 12, 240 (2002).

${ }^{115}$ G. K. Singh, A. A. Golovin, I. S. Aranson, and V. M. Vinokur, Europhys. Lett. 70, 836 (2005).

${ }^{116}$ G. K. Singh, A. A. Golovin, and I. S. Aranson, Phys. Rev. B 73, 205422 (2006).

${ }^{117}$ C. Sample and A. A. Golovin, Phys. Rev. B 74, 041606 (2006).

${ }^{118}$ G. Patermarakis, J. Chandrinos, and K. Masavetas, J. Solid State Electrochem 11, 1191 (2007).

${ }^{119}$ G. Patermarakis and K. Moussoutzanis, Electrochim. Acta 54, 2434 (2009). 
${ }^{120}$ O. Jessensky, F. Müller, and U. Gosele, Appl. Phys. Lett. 72, 1173 (1998).

${ }^{121}$ A. P. Li, F. Müller, A. Birner, K. Nielsch, and U. Gösele, J. Appl. Phys. 84, 6023 (1998).

${ }^{122}$ J. E. Houser and K. R. Hebert, J. Electrochem. Soc. 153, B566 (2006).

${ }^{123}$ J. E. Houser and K. R. Hebert, Phys. Stat. Sol. (a) 205, 2396 (2008).

${ }^{124}$ K. R. Hebert and J. E. Houser, J. Electrochem. Soc. 156, C275 (2009).

${ }^{125}$ K. R. Hebert, S. P. Albu, I. Paramasivam, and P. Schmuki, Nat. Mater. 11, 162 (2012).

${ }^{126}$ J. E. Houser and K. R. Hebert, Nat. Mater. 8, 415 (2009).

${ }^{127}$ Q. Van Overmeere, F. Blaffart, and J. Proost, Electrochem. Commun. 12, 1174 (2010).

${ }^{128}$ N. Cabrera and N. F. Mott, Rep. Prog. Phys. 12, 163 (1949).

${ }^{129}$ M. Nagayama and K. Tamura, Electrochim. Acta 12, 1097 (1967).

${ }^{130}$ M. Nagayama and K. Tamura, Electrochim. Acta 13, 1773 (1968).

${ }^{131}$ R. B. Mason, J. Electrochem. Soc. 102, 671 (1955).

${ }^{132} \mathrm{~F}$. Li, Thesis, Ph. D., University of Alabama, 1998.

${ }^{133}$ F. Li, L. Zhang, and R. M. Metzger, Chem. Mater. 10, 2470 (1998).

${ }^{134}$ M. S. Hunter and P. Fowle, J. Electrochem. Soc. 101, 514 (1954).

${ }^{135} \mathrm{~J}$. Oh, Thesis, Ph. D., Massachusetts Institute of Technology, 2010.

${ }^{136}$ C. Cheng and A. H. W. Ngan, J. Phys. Chem. C. 117, 12183 (2013).

${ }^{137}$ N. B. Pilling and R. E. Bedworth, J. Inst. Metals 29, 529 (1923).

${ }^{138}$ R. E. Smallman and A. H. W. Ngan, Physical Metallurgy and Advanced Materials (Elsevier, Amsterdam, 2007).

${ }^{139}$ C. Cherki and J. Siejka, J. Electrochem. Soc. 120, 784 (1973).

${ }^{140}$ S. J. Garcia-Vergara, L. Iglesias-Rubianes, C. E. Blanco-Pinzon, P. Skeldon, G. E. Thompson, and P. Campestrini, Proc. R. Soc. A 462, 2345 (2006).

${ }^{141}$ S. J. Garcia-Vergara, P. Skeldon, G. E. Thompson, and H. Habazaki, Electrochim. Acta 52, 681 (2006).

${ }^{142}$ P. Skeldon, G. E. Thompson, S. J. Garcia-Vergara, L. Iglesias-Rubianes, and G. E. BlancoPinzon, Electrochem. Solid State Lett. 9, B47 (2006).

${ }^{143}$ S. J. Garcia-Vergara, P. Skeldon, G. E. Thompson, and H. Habazaki, Corro. Sci. 49, 3772 (2007).

${ }^{144}$ S. J. Garcia-Vergara, P. Skeldon, G. E. Thompson, and H. Habazaki, Surf. Inerface Anal. 39, 860 (2007).

${ }^{145}$ S. J. Garcia-Vergara, P. Skeldon, G. E. Thompson, and H. Habazaki, Thin Solid Films 515, 5418 (2007).

${ }^{146}$ S. J. Garcia-Vergara, P. Skeldon, G. E. Thompson, T. Hashimoto, and H. Habazaki, J.

Electrochem. Soc. 154, C540 (2007).

${ }^{147}$ S. J. Garcia-Vergara, P. Skeldon, G. E. Thompson, and H. Habazaki, Corro. Sci. 50, 3179 (2008).

${ }^{148}$ S. J. Garcia-Vergara, T. Hashimoto, P. Skeldon, G. E. Thompson, and H. Habazaki, Electrochim. Acta 54, 3662 (2009).

${ }^{149}$ O. Jessensky, F. Müller, and U. Gösele, J. Electrochem. Soc. 145, 3735 (1998).

${ }^{150}$ J. F. Dewald, Acta. Met. 2, 340 (1954).

${ }^{151}$ J. F. Dewald, J. Electrochem. Soc. 102, 1 (1955).

${ }^{152}$ D. A. Vermilyea, Acta. Met. 1, 282 (1953).

${ }^{153}$ G. Patermarakis, J. Electroanal. Chem. 635, 39 (2009).

${ }^{154}$ S. Ono, M. Saito, M. Ishiguro, and H. Asoh, J. Electrochem. Soc. 151, B473 (2004).

${ }^{155}$ J. A. Davies, B. Domeij, J. P. S. Pringle, and F. Brown, J. Electrochem. Soc. 112, 675 (1965).

${ }^{156}$ J. A. Davies and B. Domeij, J. Electrochem. Soc. 110, 849 (1963).

${ }^{157}$ K. Nielsch, J. Choi, K. Schwim, R. B. Wehrspohn, and U. Gösele, Nano Lett. 2, 677 (2002). 
${ }^{158}$ J. D. Edwards and F. Keller, Trans. Electrochem. Soc. 79, 180 (1940).

${ }^{159}$ R. C. Spooner, J. Electrochem. Soc. 102, 156 (1955).

${ }^{160} \mathrm{Z}$. Wu, C. Richter, and L. Menon, J. Electrochem. Soc. 154, E8 (2007).

${ }^{161}$ J. L. Whitton, J. Electrochem. Soc. 115, 58 (1968).

${ }^{162}$ J. Siejka and C. Ortega, J. Electrochem. Soc. 124, 883 (1977).

${ }^{163}$ L. Young, Anodic Oxide Films (Academic Press, London, 1961).

${ }^{164}$ D. A. Vermilyea, J. Electrochem. Soc. 113, 1067 (1966).

${ }^{165}$ G. A. J. Dorsey, J. Electrochem. Soc. 113, 169 (1966).

${ }^{166}$ L. Vecchia, G. Piazzesi, and F. Siniscalco, Electrochim. Metal 2, 71 (1967).

${ }^{167}$ J. Siejka, J. P. Nadai, and G. Amsel, J. Electrochem. Soc. 118, 727 (1970).

${ }^{168}$ S. Lee and H. S. White, J. Electrochem. Soc. 151, B479 (2004).

${ }^{169}$ T. Valand and K. E. Heusler, J. Electroanal. Chem. 149, 71 (1983).

${ }^{170}$ C. Cheng, PhD Thesis, The University of Hong Kong, 2013.

${ }^{171}$ C. Cheng and A. H. W. Ngan, J. Appl. Phys. 113, 184903 (2013).

${ }^{172} \mathrm{Z}$. Su and W. Zhou, Adv. Mater. 20, 3663 (2008).

${ }^{173}$ K. Nishio, T. Yanagishita, S. Hatakeyama, H. Maegawa, and H. Masuda, J. Vac. Sci. Technol. A B26, L10 (2008).

${ }^{174}$ J. M. Montero-Moreno, M. Sarret, and C. Muller, J. Electrochem. Soc. 154, C169 (2007). 